\title{
Toxicity in vitro and in Zebrafish Embryonic Development of Gold Nanoparticles Biosynthesized Using Cystoseira Macroalgae Extracts
}

\author{
Sofia Machado',* \\ Noelia González-Ballesteros ${ }^{2, *}$ \\ Anabela Gonçalves (iD) I,3 \\ Luana Magalhães' \\ Marisa Sárria Pereira de \\ Passos $^{4,5}$ \\ Maria Carmen \\ Rodríguez-Argüelles ${ }^{2}$ \\ Andreia Castro Gomes (iD) I,3 \\ 'Centre of Molecular and Environmental \\ Biology (CBMA), Universidade do Minho, \\ Campus de Gualtar, Braga, 4710-057, \\ Portugal; ${ }^{2} \mathrm{CINBIO}$, Departamento de \\ Química Inorgánica, Universidade de \\ Vigo, Vigo, 36310, Spain; ${ }^{3}$ Institute of \\ Science and Innovation for Bio- \\ Sustainability (IB-S), Universidade do \\ Minho, Campus de Gualtar, Braga, 47I0- \\ 057, Portugal; ${ }^{4}$ International Iberian \\ Nanotechnology Laboratory (INL), \\ Braga, 47I5-330, Portugal; ${ }^{5}$ European \\ Commission, Joint Research Centre \\ (JRC), Ispra, 21027, Italy
}

*These authors contributed equally to this work

Correspondence: Andreia Castro Gomes Institute of Science and Innovation for BioSustainability (IB-S), Universidade do Minho, Departamento de Biologia, Campus de Gualtar, Braga, 47I0-057, Portugal

Tel +35I 2536015 II

Email agomes@bio.uminho.pt

Maria Carmen Rodríguez-Argüelles CINBIO, Departamento de Química Inorgánica. Universidade de Vigo, Vigo, 36310 , Spain

Tel +34986 8124I0

Email mcarmen@uvigo.es
Introduction: Research on gold nanoparticles (AuNPs) occupies a prominent place in the field of biomedicine nowadays, being their putative toxicity and bioactivity areas of major concern. The green synthesis of metallic nanoparticles using extracts from marine organisms allows the avoidance of hazardous production steps while maintaining features of interest, thus enabling the exploitation of their promising bioactivity.

Objective: To synthesize and characterize AuNPs using, for the first time, macroalga Cystoseira tamariscifolia aqueous extract (Au@CT).

Methods: Algal aqueous extracts were used for the synthesis of AuNPs, which were characterized using a wide panel of physicochemical techniques and biological assays.

Results: The characterization by UV-Vis spectroscopy, transmission electron microscopy, Z-potential and infrared spectroscopy confirmed that Au@CT were stable, spherical and polycrystalline, with a mean diameter of $7.6 \pm 2.2 \mathrm{~nm}$. The antioxidant capacity of the extract, prior to and after synthesis, was analyzed in vitro, showing that the high antioxidant potential was not lost during the synthesis. Subsequently, in vitro and in vivo toxicity was screened, by comparing two species of the genus Cystoseira (C. tamariscifolia and C. baccata) and the corresponding biosynthesized gold nanoparticles (Au@CT and $\mathrm{Au} @ \mathrm{CB}$ ). Cytotoxicity was tested in mouse (L929) and human (BJ5ta) fibroblast cell lines. In both cases, only the highest (nominal) test concentration of both extracts $(31.25 \mathrm{mg} / \mathrm{mL})$ or $\mathrm{Au} @ \mathrm{CB}(12.5 \mathrm{mM})$ significantly affected cell viability, as measured by the MTT assay. These results were corroborated by a Fish Embryo Acute Toxicity (FET) test. Briefly, it was shown that, at the highest (nominal) tested concentration $(31.25 \mathrm{mg} / \mathrm{mL}), \mathrm{CT}$ extract induced significantly higher cytotoxicity and embryotoxicity than CB extract. However, it was demonstrated that Au@CT, but not Au@CB, were generally non-toxic. At sub-lethal (nominal) test concentrations (1.25 and 2.5 mM), Au@CT affected zebrafish embryonic development to a much lesser extent than Au@CB. In vitro wound healing assays also revealed that, while other experimental conditions did not impact cell migration, CT and Au@CT displayed a moderate positive effect.

Conclusion: Au@CT and Au@CB display promising features, desirable for biomedical applications, as wound healing.

Keywords: gold nanoparticles, green synthesis, Cystoseira sp., zebrafish embryotoxicity test, bioactivity, toxicity

\section{Introduction}

In recent years, gold nanoparticles (AuNPs) have arisen as a flexible tool of major interest in the biomedical field, used as diagnosis, therapy and theragnosis agents. ${ }^{1-4}$ Such interest is related to their physicochemical, electrical and optical properties, 
which can be exploited for novel biological and chemical applications. Particularly, their high surface per volume ratio, high extinction coefficient, and the low reactivity of the gold core can favor their use in nanomedicine. ${ }^{5}$ However, in order to advance into their clinical application there is an urge to ensure the safety of AuNPs and analyze their potential hazardous effects on human health and the environment. $^{6-8}$

It has been acknowledged that the synthesis procedure employed for the obtainment of nanoparticles affects their possible toxicity. ${ }^{9}$ Traditional chemical and physical synthesis methods use hazardous reagents that can interfere with the bioavailability and bioactivity of the nanoparticles, increase their toxicity, and decrease their biocompatibility. To overcome these drawbacks, researchers have moved towards a reliable and non-toxic procedure known as green synthesis. ${ }^{10}$ Within this approach, metal nanoparticles are synthesized by the reduction of the metal ions using natural extracts, thus eliminating the need for toxic reducing agents. ${ }^{11}$ In this regard, this work focuses on the use of algae as a natural antioxidant source in the production of metallic nanoparticles.

Algae are a diverse group of eukaryotic photosynthetic organisms, and a potential source for an assortment of biomolecules, as polysaccharides, phenolic compounds, pigments, and proteins. Given the presence of relevant functional groups in these components, seaweed can be used for the synthesis of metal nanoparticles in a single step. ${ }^{12}$ Among the large number of seaweed species, this work focuses on the Cystoseira genus, a group of marine brown algae. A wide variety of biomolecules with pharmacological properties have been identified in these eukaryotes. ${ }^{13}$ For instance, the sulphated polysaccharides of some Cystoseira species show anti-radical, antiinflammatory, and gastroprotective activities. ${ }^{14}$ Also, some steroids and pigments from the Cystoseira species display antitumoral activity. ${ }^{15-17}$

Apart from their versatility, AuNPs show good biocompatibility. However, the modification of their surface can alter toxicity, biodistribution, and pharmacokinetics. ${ }^{18,19}$ Green synthesis of AuNPs was therefore hypothesized to make the most of their interesting therapeutical properties, while surmounting some of the hurdles commonly associated with conventional protocols. Also, AuNPs are usually considered non-cytotoxic and non-immunogenic, although there are a few contradictory reports in the literature. ${ }^{20,21}$ A systematic assessment of AuNPs biocompatibility, both in vitro and in vivo, using relevant model systems, is therefore of great relevance.

Zebrafish (Danio rerio, Hamilton 1822) embryos constitute a robust toxicological in vivo model to consider, mostly due to their developmental similarities with other vertebrate species, but also because of their small size, short life cycle, large number of eggs per spawning event, optical transparency, and rapid external development. Screening zebrafish embryogenesis offers indeed a unique high-throughput phenotyping, allowing for the obtainment of time-correlative toxicology data on multiple parameters in a complex vertebrate system, quickly and efficiently. $^{22-24}$ The use of this model in toxicity studies of metal nanoparticles ${ }^{25-29}$ has showed its highly informative competence, becoming a gold standard intermediate model, between in vitro mammalian cell culture studies and in vivo rodents.

In this study, we report, for the first time, on the use of C. tamariscifolia (CT) for the synthesis of gold nanoparticles (Au@CT), and the results obtained are compared to those previously gathered on seaweed C. baccata (CB). ${ }^{30}$ The study assesses whether Au@CT and Au@CB, and CT and $\mathrm{CB}$ extracts alone, affect cell viability and migration capacity using mouse (L929) and human (BJ5ta) fibroblast cell lines, by evaluating cellular metabolism using tetrazolium-based colorimetric (MTT) and wound-healing assays, respectively. To understand the correlation between in vitro and in vivo toxicity, a Fish Embryo Acute Toxicity (FET) test was performed, following test guideline 236, as recommended by the Organization for Economic Cooperation and Development (OECD).

\section{Materials and Methods}

\section{Preparation and Characterization of Algal} Extracts

Thalli of live bunches of Cystoseira tamariscifolia (CT) were collected at the lower intertidal rocky shore in the NW coast of Portugal (N $4147.858^{\prime}$ W 008 52.423'). The seaweed was either immediately employed for the extract preparation or frozen at $-20{ }^{\circ} \mathrm{C}$ for later use. The algal extract was prepared as previously reported, adjusting the seaweed:water ratio. ${ }^{30}$ Briefly, the seaweed was thoroughly rinsed with ultrapure water to remove seawater, sand, and associated biota. Then, fragments of seaweed were cut into fine pieces and placed in a double neck balloon connected to a refrigerant. Ultrapure water was added in a proportion of $0.2 \mathrm{~g} / \mathrm{mL}$ and the solution was 
then boiled at reflux during $15 \mathrm{~min}$. The extract was thus centrifuged in a Beckman coulter Microfuge 16 at $4500 \mathrm{rpm}$ for $10 \mathrm{~min}$, and the supernatant was filtered. Part of the extract obtained was stored at $4{ }^{\circ} \mathrm{C}$, and the remnant was frozen at $-20{ }^{\circ} \mathrm{C}$ until further treatment.

\section{Preparation of Au@CT}

Optimal reaction conditions for the synthesis of Au@CT were determined after several trials with different ratios of seaweed extract test concentration to gold salt test concentration. Briefly, different volumes of $\mathrm{HAuCl}_{4} 0.01 \mathrm{M}$ were slowly added to the CT extract, and the solution was kept at room temperature (RT) while stirring until colour change was observed. The different reaction conditions tested are listed in Table 1. In all cases, the reaction was followed by colour change and UV-Vis spectroscopy. To determine the exact time the reaction needed to reach completion, time measurements were recorded every 10 $\mathrm{s}$ at the maximum of absorbance wavelength. The characterization techniques employed are described in detail in the Supplementary Section.

\section{In vitro Antioxidant Activity}

The activity of the algal extract before and after the synthesis of the AuNPs was studied by three different assays: a) 1-diphenyl-2-picryl-hydrazyl (DPPH) free radical scavenging activity of the algal extract $b$ ) total phenolic content (TPC), and c) reducing power. All trials were performed by triplicate using our modified methods, ${ }^{30,31}$ and results were expressed as mean \pm standard deviation (SD).

Table I Several Reaction Conditions Tested for the Biosynthesis of Au@CT

\begin{tabular}{|l|c|}
\hline g Extract/mL $\mathbf{H}_{\mathbf{2}} \mathbf{O}$ & [Au] (mM) \\
\hline $\mathbf{0 . 2}$ & 0.1 \\
& 0.2 \\
& 0.3 \\
& 0.4 \\
\hline $\mathbf{0 . 1}$ & 0.5 \\
& 0.1 \\
& 0.2 \\
& 0.3 \\
& 0.4 \\
\hline
\end{tabular}

Abbreviation: $[\mathrm{Au}]$, gold concentration.

\section{Toxicity Assays}

Cell Metabolic Activity (MTT)

The evaluation of toxicity in vitro was determined using the MTT assay on human (BJ-5ta) and mouse (L929) fibroblast cell lines, both purchased from the American Type Culture Collection (ATCC). Cells were seeded into 96 well-microplates at a cell density of $1.2 \times 10^{6}$ (for BJ5 ta cells) and $5 \times 10^{4}$ (for L929 cells) cells $/ \mathrm{mL}$, and incubated to adhere for $24 \mathrm{~h}$ in a $5 \%$ humidified $\mathrm{CO}_{2}$ incubator at $37{ }^{\circ} \mathrm{C}$. The following day, cells were exposed to different test conditions by modifying their specific cell culture media. With that aim, stock solutions of $1 \mathrm{~g} / \mathrm{mL}$ CB extract and of $0.2 \mathrm{~g} / \mathrm{mL}$ CT extract were diluted in the respective cell culture media to prepare the (nominal) test concentrations of $31.25,6.25$ and 3.125 mg/mL. Au@CB and Au@CT were also diluted from a nanoparticles stock solution (in this case of 0.4 $\mathrm{mM}$ in gold) to prepare the (nominal) test concentrations of $12.5,2.5$ and $1.25 \mu \mathrm{M}$. Three controls were considered: negative control (viability), corresponding to cells incubated with fresh culture medium only; positive control (death), that is, cells incubated with culture medium containing 30\% (V/V) DMSO; and procedural control $\left(12.5 \% \mathrm{~V} / \mathrm{V} \mathrm{H}_{2} \mathrm{O}\right)$, related to the cells incubated with culture medium containing a similar amount of filtered water to that used to prepare the highest (nominal) test concentration of the algal extracts and the corresponding AuNPs.

After incubation, cell viability was evaluated after $2 \mathrm{~h}$ exposure to $0.5 \mathrm{mg} / \mathrm{mL}$ of MTT reagent at $37{ }^{\circ} \mathrm{C}$. Briefly, MTT tetrazolium salt was converted into an insoluble purple formazan by metabolically active cells. ${ }^{32}$ Formazan crystals were solubilized with ethanol:DMSO fresh solution $(1: 1, \mathrm{~V} / \mathrm{V})$, and absorbance was measured at 570 nm, using a SpectraMax Plus 384 Microplate Reader. Three independent experiments were conducted.

\section{Fish Embryo Acute Toxicity (FET) Test}

In vivo toxicity of $\mathrm{Au} @ \mathrm{CB}$ and $\mathrm{Au} @ \mathrm{CT}$ and related algal extracts was assessed through FET assay, in accordance with test guideline 236, and following OECD ethical standards, that is, using zebrafish embryos until 120 hours post-fertilization $\left(\mathrm{h}_{\mathrm{pf}}\right)$, thus not requiring additional ethical permits. All zebrafish embryos used came from the same laying episode. Only egg spawns displaying a fecundation rate superior to $90 \%$ were considered. Ten viable eggs per $2 \mathrm{~mL}$ were transferred at random to a 24 -wells plate, and waterborne exposed (in a semi-static regime) to the test 
conditions at $2 \mathrm{~h}_{\mathrm{pf}}$, maximizing uptake through the chorionic barrier due to its superior permeability at the earliest stages of development. ${ }^{33}$ Four replicates per test concentration were assessed. Two independent experiments were conducted. Several parameters, mostly highly conserved among vertebrates' embryogenesis, were evaluated at 8 , 32, 56 and $80 \mathrm{~h}_{\mathrm{pf}}$. At these embryonic ages, swift transformations occur that are highly informative to track early life toxic signals. This is the case of the epibolic arc perimeter, which permits to identify abnormal embryonic growth patterns, serving (indirectly) as an indicator to assess lipid trafficking. Heart beating is another relevant embryonic trait, as it provides insights on particle propensity to cross the biological barriers. To assess cardiotoxic effects, twenty zebrafish embryos were randomly selected, and the number of heartbeats was counted for $10 \mathrm{~s}$. In order to avoid bias, "blind" records were executed by a single operator. A morphometric analysis of the chorion, yolk, eye, and pupil was conducted using a IX71 Inverted Fluorescent Microscope (Olympus), and measured to the nearest micrometer, using Image Tool (v 3.0, US).

CB and CT extracts and related Au@CB and Au@CT solutions were prepared by dilution of the respective stock in HEPES E3 buffer (HEPES $15 \mathrm{mmol} / \mathrm{L}$ with $5 \mathrm{mmol} / \mathrm{L}$ $\mathrm{NaCl}, 0.17 \mathrm{mmol} / \mathrm{L} \mathrm{KCl}, 0.33 \mathrm{mmol} / \mathrm{L} \mathrm{CaCl}_{2}$ and 0.33 $\mathrm{mmol} / \mathrm{L} \mathrm{MgSO}_{3}$ or $\mathrm{MgSO}_{4}, \mathrm{pH}=7.2$, prepared in ultrapure water), known as Embryo Medium, in order to obtain the established test (nominal) concentrations, as was done in the MTT assay. HEPES E3 was thus used as experimental control. Adequate environment temperature was ensured at soaking by pre-heating the prepared solutions at $26 \pm 1{ }^{\circ} \mathrm{C}$ and on daily renewal, as recommended by OECD 2013. Plates were incubated under a controlled photoperiod (14 h light, $10 \mathrm{~h}$ dark). To prevent crosscontamination, wells were inspected several times a day to remove coagulated embryos. An experiment was classified as valid for an embryonic lethality threshold set at $10 \%$. Other experimental details not mentioned were considered as described at. ${ }^{34}$

\section{Wound Healing Assay}

Cell migration and proliferation were assessed through the scratch assay to evaluate the migration capacity of the BJ5ta and L929 cell lines. Cell migration was observed and recorded using a IX71 Inverted Fluorescent Microscope. The area free of cells at $0,14,18$ and $22 \mathrm{~h}$ was quantified in pixels with the MRI Wound Healing Tool macro for open-software platform ImageJ, and the percentage of reduction in scratch area between the first and last time points was calculated. Cells were seeded into 12 well-microplates at a cell density of $2 \times 10^{5}$ (for BJ5ta) and $8 \times 10^{4}$ (for L929) cells $/ \mathrm{mL}$, and incubated for $24 \mathrm{~h}$ in a $5 \%$ humidified $\mathrm{CO}_{2}$ incubator at $37{ }^{\circ} \mathrm{C}$. This assay was performed following two different strategies: 1) the cells were incubated with the $\mathrm{CB}$ and $\mathrm{CT}$ extracts, and $\mathrm{Au} @ \mathrm{CB}$ and $\mathrm{Au} @ \mathrm{CT}$ test (nominal) concentrations prior to the scratch of the confluent cell culture; 2) the scratch was performed, and the cells were subsequently incubated with the CB and CT extracts, and Au@CB and Au@CT test (nominal) concentrations. A negative control (life) was considered, where cells were incubated with specific culture media only. Three independent experiments were conducted.

\section{Statistics}

Prior to data analysis, parametric assumptions were met for normality (Shapiro-Wilk test) and homogeneity of variances (Levene's test). One-factor analysis of variance (ANOVA or Kruskal-Wallis) was carried out to determine significant differences among the antioxidant activity assays. Post-hoc testing was conducted using Tukey's or Dunn's multiple comparisons. A $P$ value of 0.05 was considered for significance testing. Analyses were performed using Prism v 6.0 (GraphPad Software Inc., US). The results of this analysis are indicated in the Figures or Tables.

Factorial ANOVA (two factors: time of exposure (two levels: $24 \mathrm{~h}$ and $48 \mathrm{~h}$ ) and test condition (five levels: algae extracts and their AuNPs at three nominal concentrations, procedural control and death control)) was conducted to determine differences on cell metabolic activity of the fibroblasts.

Regarding the FET assay, to investigate exposure effects of the algae extracts and their AuNPs on zebrafish embryos spontaneous movements and cumulative survival, a chi-square $\left(\chi^{2}\right)$ test was performed considering the values observed for each test concentration. The null hypothesis of "no differences among groups" was considered for the setting of the expected values (average percentage of embryos exhibiting spontaneous movements, or total embryonic survival at $80 \mathrm{~h}_{\mathrm{pf}}$, of all treatments). Onefactor ANOVA was considered to assess the statistical significance of the effects on zebrafish embryos epiboly, head-trunk angle, heart and hatching rates, total body length $\left(\mathrm{L}_{\mathrm{T}}\right)$, and free swimming. An ANCOVA analysis was conducted to avoid biases related to covariates while investigating effects on zebrafish yolk volume (egg 
volume was used as co-variable), pupil surface (eye surface was used as co-variable), and yolk extension $\left(\mathrm{L}_{\mathrm{T}}\right.$ was used as co-variable).

In order to identify a protective and/or regenerative effect by $\mathrm{CB}$ and $\mathrm{CT}$ extracts and their AuNPs, a MANOVA analysis was conducted to detect differences on fibroblasts proliferation and migration upon pre- and post-exposure of two test (nominal) concentrations, over $22 \mathrm{~h}$.

Post hoc comparisons were conducted using StudentNewman-Keuls (SNK). A $P$ value of 0.05 was considered for significance testing. Analyses were performed using STATISTICA v.8.0 (StatSoft, US).

\section{Results and Discussion}

\section{Synthesis and Characterization of Au@CT}

As previously mentioned, in this work, the synthesis of the AuNPs employing aqueous extracts of the brown seaweed C. tamariscifolia was performed for the first time. Although the baseline protocol used was the one used for the synthesis of $\mathrm{Au} @ \mathrm{CB},{ }^{30}$ some adjustments were made. Accordingly, several experiments were carried out until nanoparticles with homogeneous size and shape distribution were obtained.

During the synthesis, a colour change from pale brown to red/purple occurred when the Au@CT were formed. The appearance of the characteristic Surface Plasmon Resonance (SPR) band of gold nanoparticles can be observed in the UV-Vis spectrum, at around $500 \mathrm{~nm}$. UVVis spectra of nanoparticles synthesized with the CT extract at a test concentration of $0.2 \mathrm{~g} / \mathrm{mL}$, and with growing test concentrations of gold from 0.1 to $0.5 \mathrm{mM}$ can be observed in Figure 1A. At test concentrations of 0.1 and $0.2 \mathrm{mM}$ of gold, the spectra obtained show a broad band, while at higher test concentrations the spectra obtained display thinner and more intense bands with a slight peak shift to higher wavelengths, more specifically, from $537 \mathrm{~nm}$ to $541 \mathrm{~nm}$.

The spectra obtained when using a diluted algal extract $(0.1 \mathrm{~g} / \mathrm{mL})$ and gold concentrations between 0.1 and $0.5 \mathrm{mM}$ are represented in Figure 1B. In this case, the impact of the increase in the concentration of gold on peak broadening was undetectable, with just an expected increase in peak intensity with higher gold concentrations. It should also be noted that the difference in wavelength with these samples is higher than in the first case, with a wavelength shifting from 534 to 545 $\mathrm{nm}$ with increasing gold concentrations. Higher concentrations of gold were not tested since both samples with gold concentration of $0.5 \mathrm{mM}$ precipitated after $24 \mathrm{~h}$, even when preserved at $4{ }^{\circ} \mathrm{C}$. Therefore, the AuNPs prepared with 0.1 and $0.2 \mathrm{~g} / \mathrm{mL}$ of CT extract and $0.4 \mathrm{mM}$ of gold were selected for detailed characterization using Transmission Electron Microscopy (TEM) analysis, to determine the size and shape of the nanoparticles.

In order to analyse the reaction process in detail, UVVis spectra at the maximum wavelength absorbance were recorded every $10 \mathrm{~s}$. Figure $1 \mathrm{C}$ shows the results obtained for $0.2 \mathrm{~g} / \mathrm{mL}$ of CT extract and $0.4 \mathrm{mM}$ of gold. It can be observed that the reaction started in the first seconds after the addition of the $\mathrm{HAuCl}_{4}$, and a quick increase in the absorbance was recorded within the first $5 \mathrm{~min}$, after which stabilization occurred. The spectrum was measured for $1 \mathrm{~h}$, but it can be observed that stabilization occurred in the first $20 \mathrm{~min}$.

When comparing these results with the ones obtained for $\mathrm{Au} @ \mathrm{CB},{ }^{30}$ the synthesis with $C$. baccata seems quicker than the one with $C$. tamariscifolia, with the reaction finishing after just $5 \mathrm{~min}$. This could be due to the higher concentration of $\mathrm{CB}$ extract employed during the synthesis.

With the aim of assessing the stability of the AuNPs, Z-potential was measured. The values obtained for $\mathrm{Au} @ \mathrm{CB}$ and Au@CT were $-30.7 \pm 2.0 \mathrm{mV}$ and $-24.6 \pm$ $1.5 \mathrm{mV}$, respectively, indicating that the former are highly stable due to their stronger surface charge, while the latter are moderately stable. ${ }^{35}$

Figure 2 shows the low magnification TEM images acquired for the two selected samples. In both cases, the mean diameter was calculated by the measurement of at least 100 AuNPs, and the size distribution histograms were built. In the two samples, it can be observed that the AuNPs show a darker contrast when compared with the algal extract, due to the higher electron density of gold. It was also observed that the AuNPs were mostly confined to the algal extract matrix, even after all the centrifugation and washing steps had been performed. The AuNPs obtained with a concentration of algal extract of $0.2 \mathrm{~g} /$ $\mathrm{mL}$ (Figure 2A) are spherical and have a significantly higher homogeneity in size and shape than those obtained with $0.1 \mathrm{~g} / \mathrm{mL}$ of algal extract (Figure 2B), presenting a size distribution of $7.6 \pm 2.2 \mathrm{~nm}$ and $14.0 \pm 6.0 \mathrm{~nm}$, respectively. Therefore, the appropriate reaction conditions for the synthesis of the Au@CT were achieved when using 

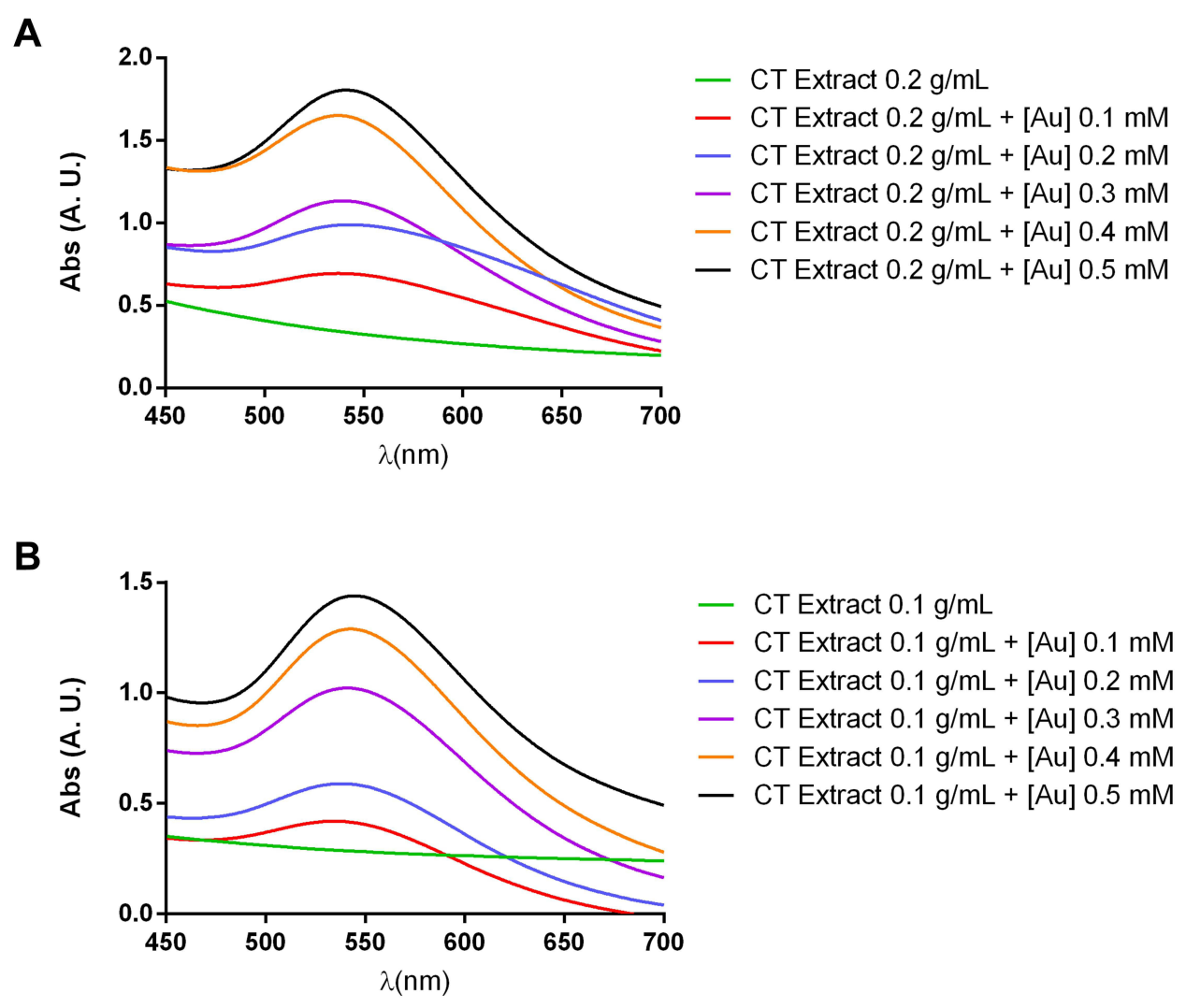

C

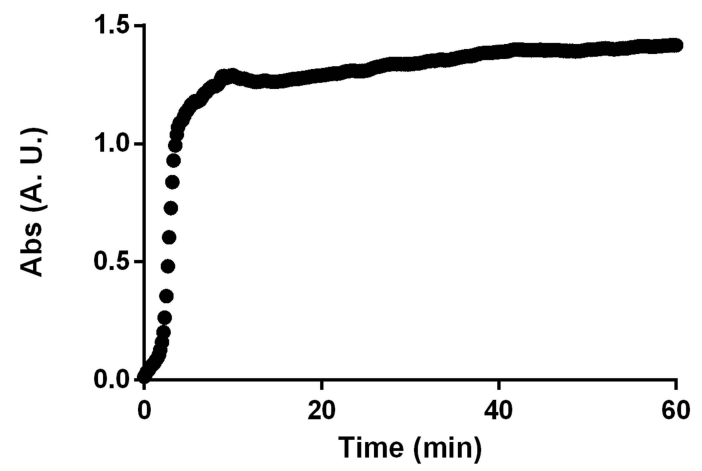

Figure I UV-Vis spectra of gold nanoparticles synthesized from C. tamariscifolia (Au@CT) under different reaction conditions (A and B). Time course absorbance measurements of Au@CT synthesized with CT extract at $0.1 \mathrm{~g} / \mathrm{mL}$ and with $0.4 \mathrm{mM}$ of gold (C).

Abbreviation: $\mathrm{AU}$, arbitrary units.

$0.2 \mathrm{~g} / \mathrm{mL}$ of algal extract and $0.4 \mathrm{mM}$ of gold, incubating at RT.

To the best of our knowledge, this study is the first report on the preparation of AuNPs employing an algal extract from C. tamariscifolia. However, our previous work on the synthesis of AuNPs led by $C$. baccata can be used for comparison with the present results. In that study, the optimal reaction conditions for the synthesis were obtained at a higher concentration of the algal extract $(1 \mathrm{~g} / \mathrm{mL})$ and the same concentration of gold $(0.4 \mathrm{mM})$, obtaining Au@CB with a maximum wavelength at $532 \mathrm{~nm}$ and a mean diameter of $8.4 \pm 2.2 \mathrm{~nm}$, which is slightly larger than the size obtained with CT extract. ${ }^{30}$

For the study of the crystalline nature of $\mathrm{Au} @ \mathrm{CT}$, High-Resolution Transmission Electron Microscopy (HRTEM) images were also obtained. The acquisition of high-resolution microscopy in this type of samples is challenging due to the abundant presence of organic compounds, which can easily lead to contamination of the samples and loss of resolution. In Figure 3A, one 

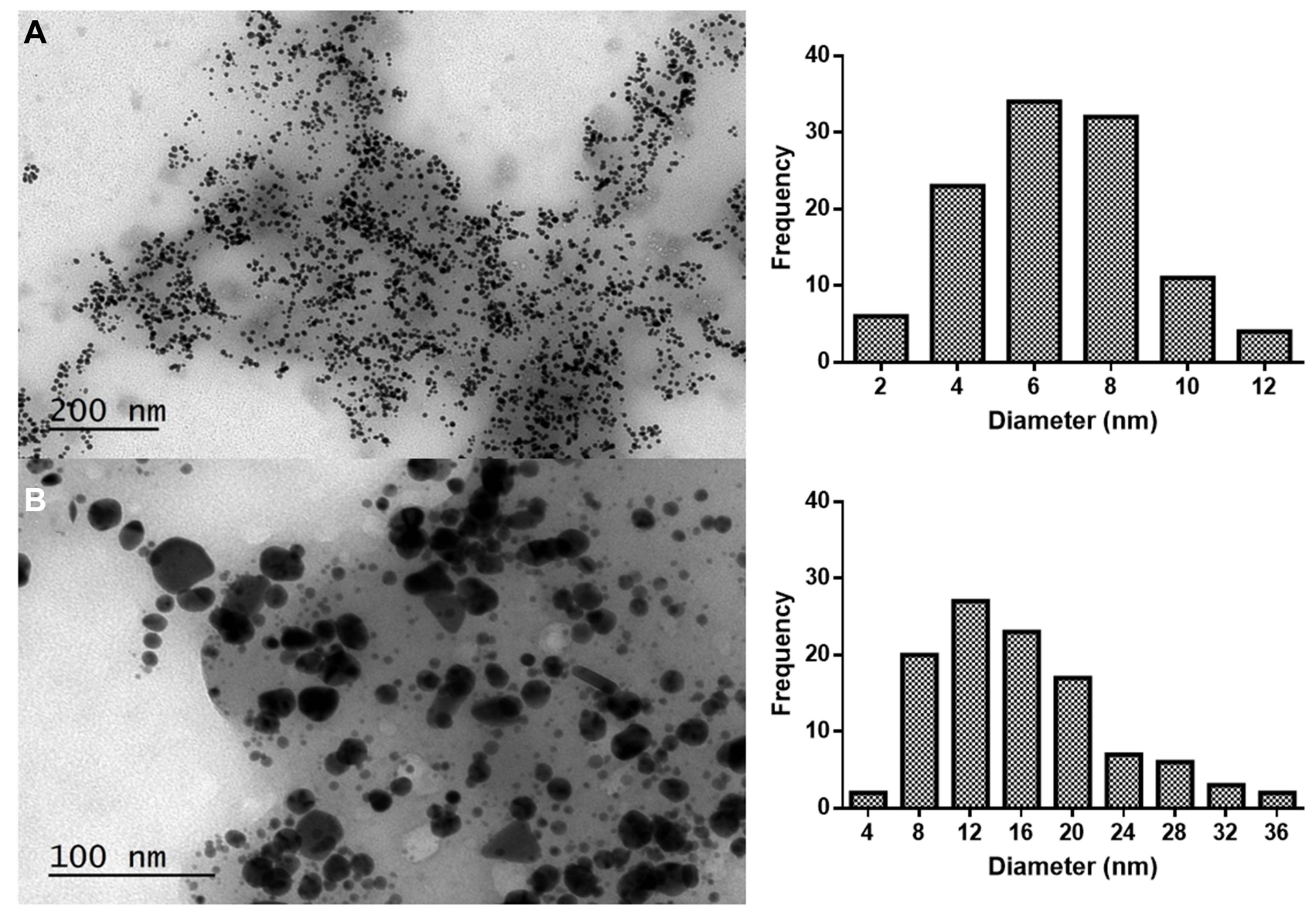

Figure 2 Low magnification TEM images of gold nanoparticles synthesized with (A) $0.2 \mathrm{~g} / \mathrm{mL}$ and (B) $0.1 \mathrm{~g} / \mathrm{mL}$ of $C$. tamariscifolia extract and $0.4 \mathrm{mM}$ of gold, and their corresponding size distribution histogram.

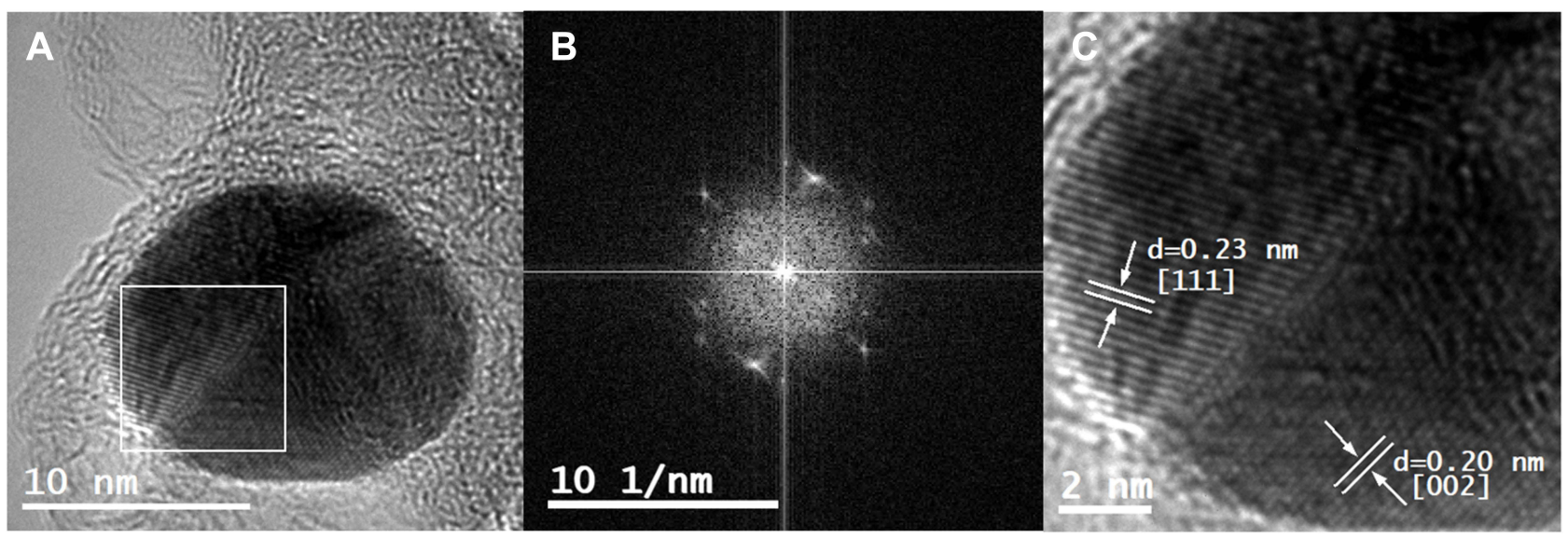

Figure 3 (A) HRTEM image of Au@CT; (B) Fourier capture showing the polycrystalline nature of Au@CT; (C) amplification of the selected area showing interplanar distance of the Au@CT crystalline structure, with the calculated d-spacing and corresponding Miller index.

nanoparticle with an internal complex contrast surrounded by an amorphous mass, corresponding to the CT extract, can be observed. The study of the Fourier transform (Figure 3B) clearly confirmed that the NPs investigated were polycrystalline, due to the appearance of several disorder points instead of an ordered pattern.

The d-spacing of the crystalline structure of the nanoparticle selected was then calculated in the marked area. 
The corresponding Miller indices were assigned on the basis of tabulated data. As shown in Figure 3C, d-spacings of 0.23 and $0.20 \mathrm{~nm}$ were measured, corresponding to the Miller index values of [111] and [002], respectively. The results confirmed a crystalline structure for gold, which corresponds to a face centred cubic unit cell.

In Figure 4A, a DF-STEM image is shown. Given the $\mathrm{Z}$ contrast of this kind of image, it can be appreciated that the Au@CT with brighter contrast are present inside the organic mass of the CT extract, which appears in darker contrast.

An Energy Dispersive X-ray Analysis (EDX) was performed to study the elemental composition of the Au@CT, as it can be observed in Figure 4C. Apart from gold, the presence of other elements in the seaweed, as $\mathrm{C}, \mathrm{Cl}, \mathrm{K}$, $\mathrm{I}$ and $\mathrm{O}$, was confirmed. Some of these elements have been reported to be part of the composition of $\mathrm{CT}^{36,37}$ The signal of $\mathrm{Cu}$ that appeared in the spectrum could be due to the copper grid where the samples were prepared. However, it cannot be excluded as part of the composition of the CT extract, since it has been reported as a common element in the composition of different brown seaweed. ${ }^{38,39}$
From the EDX spectra, the elemental maps of the samples were obtained by selecting carbon and gold as imaging agents. The resulting image confirmed the presence of a layer of carbon surrounding the metallic surface of the AuNPs (see Figure 4B). It can be observed that the signal from gold appears on the nanoparticles and not in the CT extract, suggesting that no gold(III) is present in the sample. EDX analysis is not the best technique for the detection of light elements $(Z<11)$. Therefore, Electron Energy-Loss Spectroscopy (EELS) analysis was performed in order to obtain more data about the organic nature of the samples. The analysis was performed in areas of the sample over a hole to eliminate the contribution of the composition of the grid. In the EELS spectra (Figure 4D), the characteristic edge of the C element (284 $\mathrm{KeV}), \mathrm{N}(401 \mathrm{KeV})$ and $\mathrm{O}(532 \mathrm{KeV})$ can be observed. The results obtained in the electron microscopy analysis confirm the organic nature of the mass that surrounds the gold nanoparticles. It can be confirmed that these are confined inside the CT extract matrix, which acts not only as reducing agent, but also as a stabilizer, preventing their aggregation and precipitation.

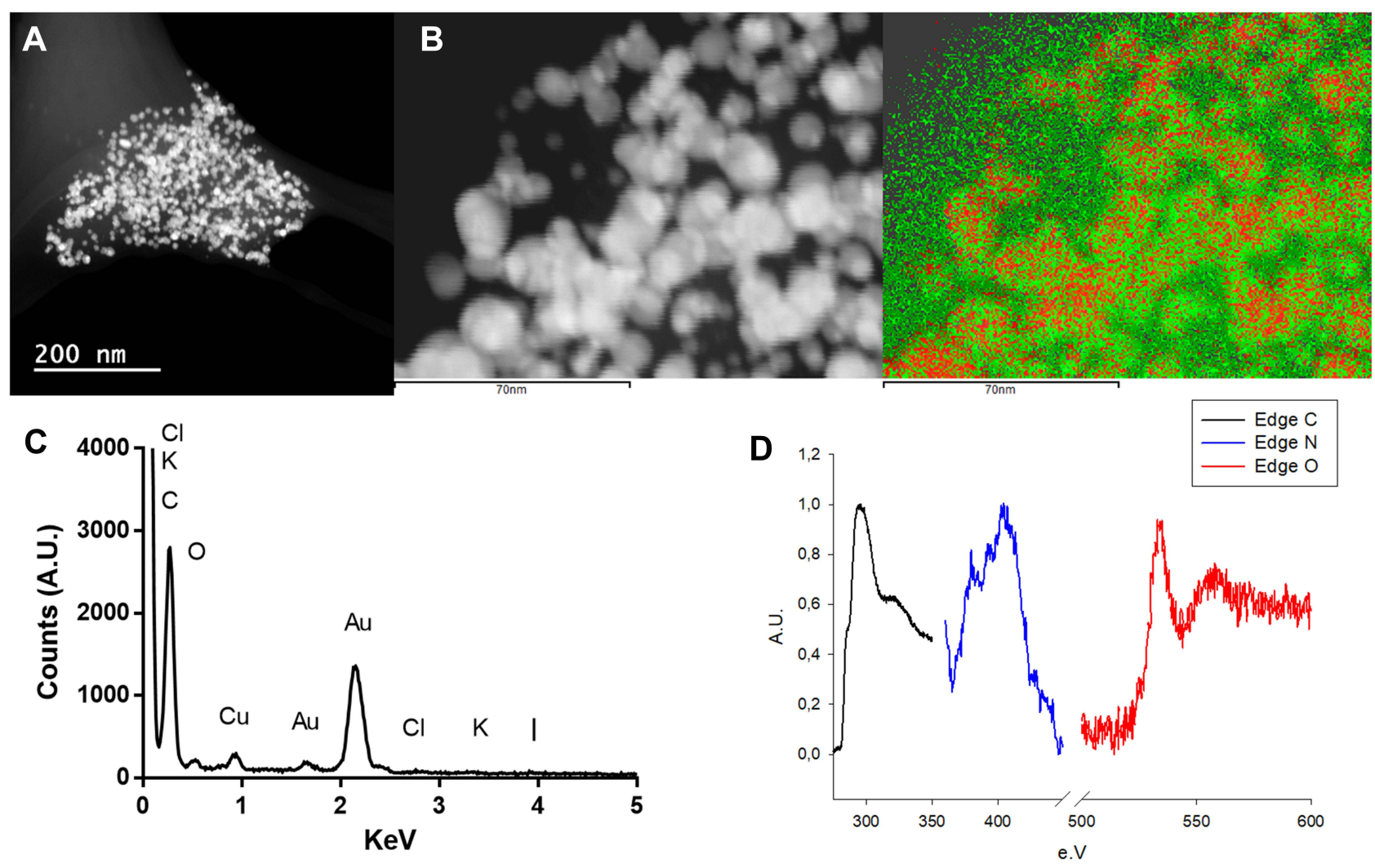

Figure 4 (A) DF-STEM images showing Z-contrast, (B) elemental mapping image, (C) EDX and (D) EELS spectra of Au@CT. Abbreviation: $A U$, arbitrary units. 
FTIR spectral analysis was performed to identify the functional groups of the components present in the seaweed extract, and the changes it suffered after the synthesis of Au@CT. The assignation of the bands was made on the basis of other studies. ${ }^{36,40}$ Furthermore, for the sake of comparison, the FTIR spectrum of the commercial polysaccharide fucoidan, a well-known sulfated polysaccharide extracted from brown seaweed, ${ }^{41}$ was also acquired. The spectra obtained and the assignment of the peaks are shown in Figure 5.

When comparing the spectrum of fucoidan with the ones obtained for the seaweed extract, the presence of the bands assigned to the polysaccharide can be confirmed, with some shifts and changes in the relative intensity. The appearance of new bands can also be noted. These changes could be due to the complex composition of the aqueous extract, which is expected to be a mixture of the soluble components of the seaweed. Since aqueous extraction is not selective, other biomolecules apart from polysaccharides are also extracted, for example, polyphenols and proteins. Therefore, it can be suggested that the difference observed between the two spectra is due to the presence of these molecules in combination with fucoidan.

When comparing CT with Au@CT FTIR spectra, the shifts in the wavelength and intensity of the bands may identify the principal functional groups, which might be involved in the synthesis and stabilization of the Au@CT The strong broad band that appears in both spectra between 3400 and $3300 \mathrm{~cm}^{-1}$ is typically assigned to $\mathrm{NH}$ and $\mathrm{OH}$ stretching vibrations of the amino or hydroxyl groups of proteins or sugar. ${ }^{38}$ Aliphatic C-H groups stretching vibrations are assigned to the weak band at $2930 \mathrm{~cm}^{-1}$. Asymmetrical and symmetrical stretching of the carboxylate groups from amide I and II of proteins are assigned to the two bands at around 1600 and $1400 \mathrm{~cm}^{-1}$, respectively. ${ }^{42}$ Bands between 1200 and $900 \mathrm{~cm}^{-1}$ are common to all polysaccharides and these are mainly attributed to $\mathrm{C}-\mathrm{C}$ and $\mathrm{C}-\mathrm{O}$ stretching bonds and glycosidic C-O-C vibrations. ${ }^{43}$ Among the bands that appear in that region, the sugar ring and glycosidic bond stretching vibrations are assigned to the band at $1080 \mathrm{~cm}^{-1}$. 44,45 Finally, the presence of sulphate groups in the polysaccharide structure is confirmed by the appearance of C-O-S and S-O stretching vibration at 800 and $1250 \mathrm{~cm}^{-1}$, respectively. ${ }^{46}$ The analysis of the shifts observed in the main bands of both spectra shows a shift towards higher wavelengths, from 3391 to $3421 \mathrm{~cm}^{-1}$. This result suggests the participation of the hydroxyl functional groups from polyphenols and polysaccharides. Furthermore, the shift could be the result of the involvement of the amino groups of proteins in the bioreduction of the gold(III) salt. Also, the sulfonic groups from

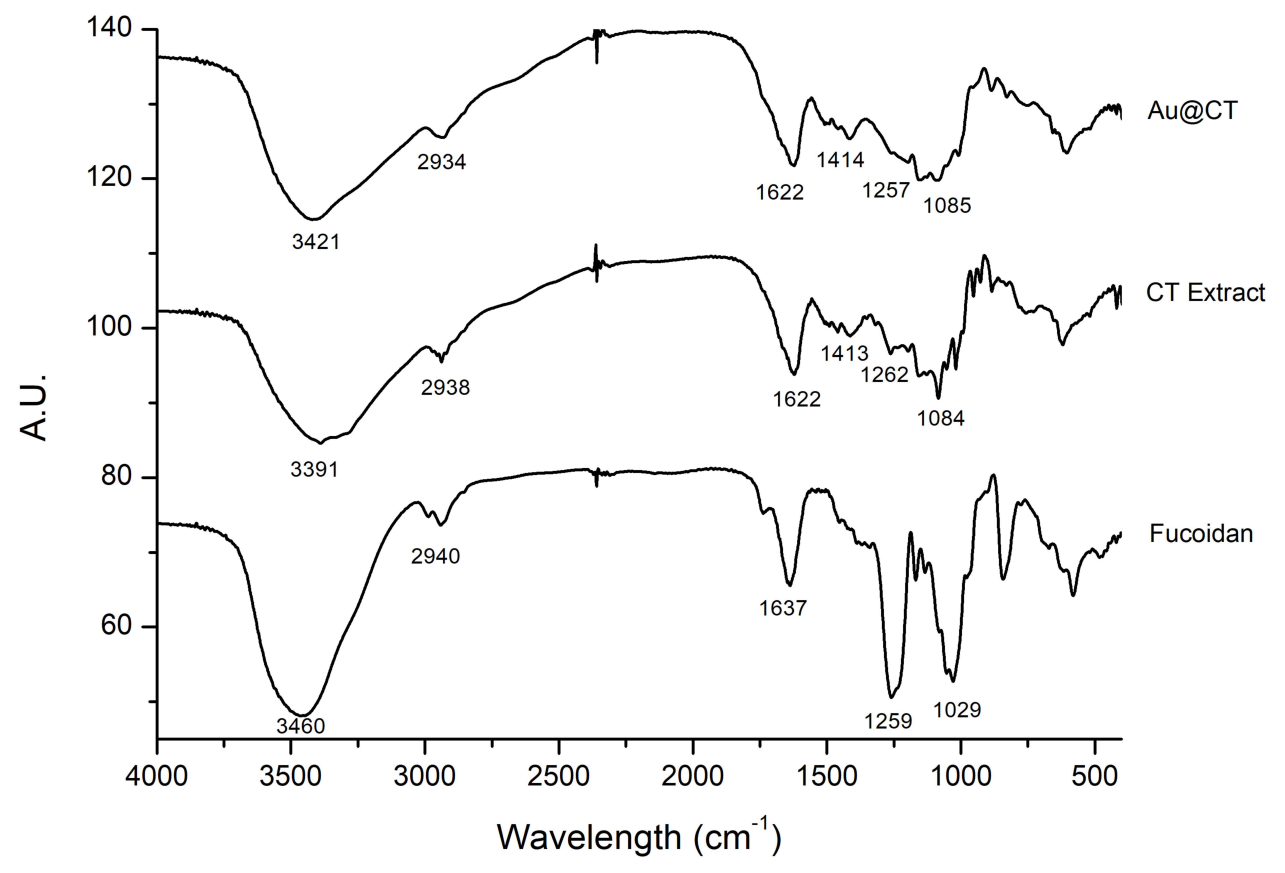

Figure 5 FTIR spectra of CT extract and Au@CT, compared to fucoidan. Abbreviation: $A U$, arbitrary units. 
polysaccharides could be involved in metal binding and stabilization of the Au@CT, as shown by the shift from 1262 to $1257 \mathrm{~cm}^{-1}$. These results are in accordance with the ones obtained for C. baccata. The main bands appear at similar wavelengths, and the major variations are found in the bands centered at 3400 and $1200 \mathrm{~cm}^{-1}$. 30

\section{In vitro Antioxidant Activity}

The antioxidant capacity of the CT extract before and after the synthesis of Au@CT was analyzed by the determination of the reducing power, amount of total phenolic compounds, and DPPH radical scavenging activity. Furthermore, for comparison purposes, the antioxidant activity of $\mathrm{CB}$ extract is also reported on. Results are collected in Table 2 . These assays provide information regarding the potential of the $\mathrm{CT}$ extract to act as a reducing agent and the change observed after the synthesis of Au@CT.

To the best of our knowledge, this is the first report on the reducing activity of $C$. tamariscifolia and the results confirm the presence of reductants in the algal extract. It presents a strong antioxidant activity, and it can be observed that $\mathrm{CT}$ extract possesses 3 times more reducing power than the algal extract of C. baccata. $^{30}$ Also, TPC present in the CT extract was also determined. A direct correlation between TPC and reducing power has been previously reported on, and it can be observed that $\mathrm{CT}$ extract possesses almost four times more phenolic content than $\mathrm{CB}$ extract. Previously, other authors have reported different values of TPC of C. tamariscifolia, but comparison between the results is a difficult task since a standard method is not available. For instance, Abdala-Diaz et al reported on the TPC of methanolic extracts of three parts of C. tamariscifolia as $\mathrm{mg}$ phloroglucinol/g dry weight (DW). ${ }^{47}$ In the same way, Celis-Pla et al expressed the results as $\mathrm{mg}$ phloroglucinol/g DW for methanolic extracts of the fronds. ${ }^{48}$ Custódio et al reported that $\mathrm{CT}$ possesses higher values of TPC than other algae from the same genus, obtaining a value of $105.0 \pm 6.9$ and $59.9 \pm 3.7 \mathrm{mg} \mathrm{GAE} / \mathrm{g}$
DW for methanolic extracts of $C$. tamariscifolia and Cystoseira nodicaulis, respectively. ${ }^{49}$

The significant difference between our results and the ones found in the literature may be due to the different sample preparation protocol, and the solvent used in the extraction. For instance, Pinteus et al reported the TPC of CT when using methanol or dichloromethane, obtaining the significantly different values of $57.52 \pm 0.037$ and 0.51 $\pm 0.001 \mathrm{mg} \mathrm{GAE} / \mathrm{g}$ extract, respectively, ${ }^{50}$ while Samri et al reported that the TPC varied from $3.18 \pm 0.821$ to $29.33 \pm 0.258 \mathrm{mg} \mathrm{GAE} / \mathrm{g}$ of extract when using methanol, dichloromethane, ethyl acetate, methanol/water (60/40) and the dichloromethane/methanol (50/50)..$^{51}$

Finally, the study of DPPH revealed that the CT extracts contain free radical scavengers. As shown in Table 2, there is a direct relationship between the reducing power and the TPC, with the half maximal effective concentration (that is, $\mathrm{EC}_{50}$ ) values of the $\mathrm{DPPH}$ scavenging activity. CT extract possesses an $\mathrm{EC}_{50}$ value four times lower than that obtained for $\mathrm{CB}$ extract, indicating a higher scavenging activity in the case of the former. Data from the literature is varied and, in some cases, difficult to use for comparison. Andrade et al reported an $\mathrm{EC}_{50}$ value of $0.58 \mathrm{mg} \mathrm{DW} / \mathrm{mL}$ for an ethanolic extract, ${ }^{52}$ while in the case of a methanolic extract Celis-Pla et al obtained values of $0.2-0.3 \mathrm{mg} \mathrm{DW} / \mathrm{mL}^{48}$ It has been reported in a relatively recent study that ochrophytes belonging to the Cystoseira genus have the highest scavenging potential, especially C. tamariscifolia $(92 \%$ at $1 \mathrm{mg} / \mathrm{mL})$, when compared with other 20 species of green, red and brown seaweed. ${ }^{49}$

As previously mentioned, the three antioxidant activity assays were also performed for the formulations Au@CT and $\mathrm{Au} @ \mathrm{CB}$. In the case of the reducing power, a significant decrease in the values obtained can be appreciated in both AuNPs. Regarding TPC, a significant decrease was observed in Au@CT, while no difference was detected in the case of $\mathrm{Au} @ \mathrm{CB}$. This suggests that the phenolic compounds present in $\mathrm{CT}$ extract play an

Table 2 In vitro Antioxidant Activity of Algae Extracts and Their AuNPs

\begin{tabular}{|l|c|c|c|c|}
\hline & CT Extract & Au@CT & CB Extract & Au@CB \\
\hline Reducing activity $(\mathrm{mg}$ ascorbic acid/g algae) & $1783.6 \pm 60.2^{\mathrm{a}}$ & $1344.2 \pm 60.7^{\mathrm{b}}$ & $583.1 \pm 17.1^{\mathrm{c}}$ & $352.3 \pm 15.2^{\mathrm{d}}$ \\
Total phenolic content $(\mathrm{mg}$ gallic acid/g algae) & $9.26 \pm 0.34^{\mathrm{a}}$ & $6.15 \pm 0.2 \mathrm{I}^{\mathrm{b}}$ & $2.41 \pm 0.09^{\mathrm{c}}$ & $2.47 \pm 0.21^{\mathrm{c}}$ \\
DPPH scavenging activity $\left(\mathrm{EC}_{50} \mathrm{mg} / \mathrm{mL}\right)$ & $3.66 \pm 0.02^{\mathrm{a}}$ & $3.13 \pm 0.1 \mathrm{I}^{\mathrm{a}}$ & $12.65 \pm 0.18^{\mathrm{b}}$ & $30.20 \pm 0.80^{\mathrm{c}}$ \\
\hline
\end{tabular}

Notes: Values represent averagetstandard error $(n=3)$; For the same row, different superscript letters are significantly different $($ One-way ANOVA and Tukey's multiple comparisons test, $P<0.05)$. 
active role in the reduction process for the synthesis of the $\mathrm{Au} @ \mathrm{CT}$. In the case of the DPPH, a different behaviour was detected, with a significant increase in Au@CT and a decrease in Au@CB.

\section{Cytotoxicity Assessment}

Any nanosystem with potential for biomedical applications must undergo a thorough safety assessment. For this purpose, two normal mammalian fibroblast cell lines (BJ5ta and L929) were selected, widely used as references for in vitro screening of the cytotoxic effects and bioactivity of different nanomedicines. In this way, cytotoxicity was assessed according to international ISO guidelines, which set a cell viability superior to $80 \%$ as a non-toxic effect. Thus, MTT assay was

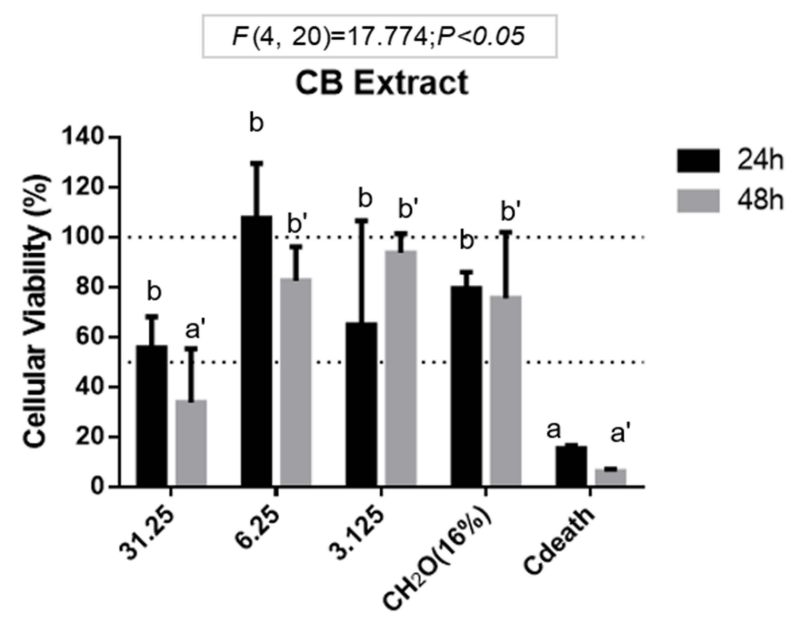

Extract concentrations $(\mathrm{mg} / \mathrm{mL})$

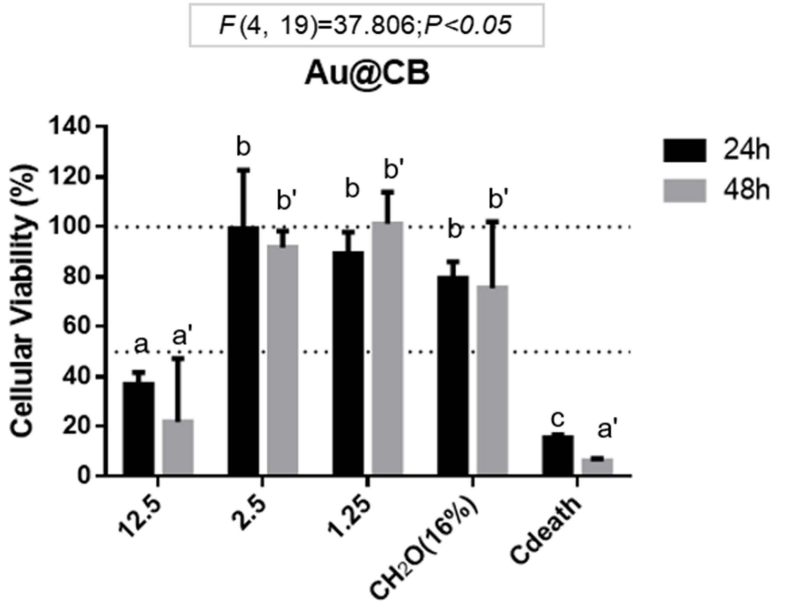

Au@CB concentrations $(\mu \mathrm{M})$ performed and results were analyzed relatively to the life control, which was considered as $100 \%$ of cell viability, and represented by the line $Y=100$. The line $Y=50$ represents the half percentage of viability for all the graphs.

The results obtained on L929 fibroblasts demonstrate that, regardless of the time of exposure, $\mathrm{Au} @ \mathrm{CB}$ caused a significantly statistical cytotoxic effect at the highest (nominal) test concentration $(12.5 \mu \mathrm{M}$, SNK data not shown), but Au@CT were generally well tolerated by cells at the considered range, as no significant differences among (nominal) test concentrations were detected (see Figure $6 \mathrm{C}$ and $\mathrm{D}$ ).

Cell viability was similarly assessed in BJ5ta (see Figure S1). The results obtained corroborate

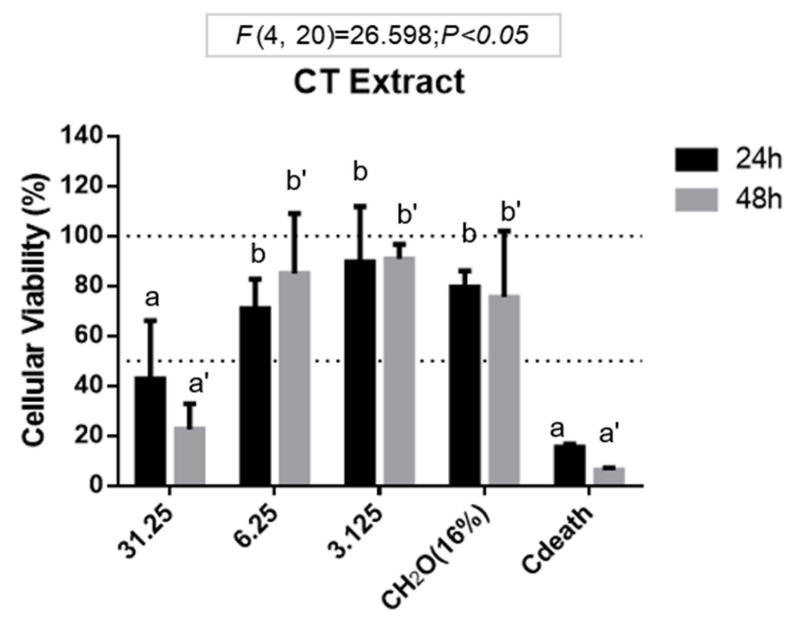

Extract concentrations $(\mathrm{mg} / \mathrm{mL})$

$F(4,20)=48.048 ; P<0.05$

$\mathrm{Au} @ \mathrm{CT}$

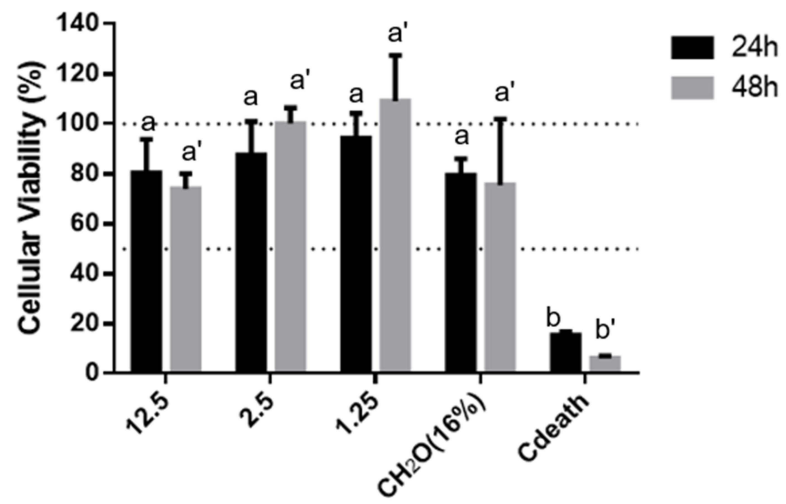

Au@CT concentrations ( $\mu \mathrm{M})$

Figure 6 MTT data on exposure of CB and CT extracts (A and B, respectively), and the correspondent Au@CB and Au@CT (C and D, respectively) to mammalian (L929, mouse) fibroblast cells, for 24 and $48 \mathrm{~h}$.

Notes: Error bars represent mean \pm SEM of three independent experiments. Different letters indicate significant differences among (nominal) test concentrations of the algae extracts and their AuNPs, independently. 
those recorded with L929, although the human fibroblasts were generally less sensitive to the test conditions.

In general, the incubation of cells with algae extracts induced more toxicity at any (nominal) test concentration than with the AuNPs, particularly with CB extract. This is clearly visible by comparing the cytotoxicity results for $12.5 \mu \mathrm{M} \mathrm{Au} @ \mathrm{CB}$ with the corresponding $\mathrm{CB}$ extract concentration, $6.25 \mathrm{mg} / \mathrm{mL}$ (Figure $6 \mathrm{~A}$ and C). These results are in accordance with a previous study, where Au@CB also proved to be non-toxic for other normal cell lines, but were selectively toxic to tumor cells, suggesting their potential for cancer treatment. ${ }^{30}$ Other authors also reported similar selective cytotoxicity against tumoral cell lines, but not human umbilical HUVEC cells by extracts of CT. ${ }^{15}$ This effect is possibly mediated by the promotion of apoptosis, which is also in agreement with the data gathered on $\mathrm{Au} @ \mathrm{CB}^{30}$ As our results show, Au@CB were more toxic than Au@CT at any (nominal) test concentration, although other studies have referred to a similar potential for selectively targeting cancer cells. Therefore, their applicability should be considered taking into account the algae species used.

\section{In vivo Toxicity (FET Test)}

In order to extend the in vitro cytotoxic data, a robust vertebrate model was assessed in vivo. Zebrafish eggs at the cleavage embryonic developmental age were thus exposed to the algal extracts and their AuNPs by following a FET assay under OECD test guideline 236. To our knowledge, the FET test had never been used before to assess the (eco)toxicity of Cystoseira extracts or the biosynthesized AuNPs. In fact, there are very few reports on biosynthesized nanoparticles in which zebrafish were used, either as embryos or adults. ${ }^{53}$

When analyzing results on zebrafish embryonic cumulative survival (Figure 7), a toxicity trend equivalent to that measured in vitro on cellular models was readily perceived. Specifically, it was shown that CT extract at the highest (nominal) test concentration caused a significantly higher embryotoxic effect than that recorded in the case of $\mathrm{CB}$ extract (see Figure 7A and B). However, also corroborated by the cytotoxic data was the fact that nanoparticles synthesized with CT extract (Au@CT) efficiently resolved the
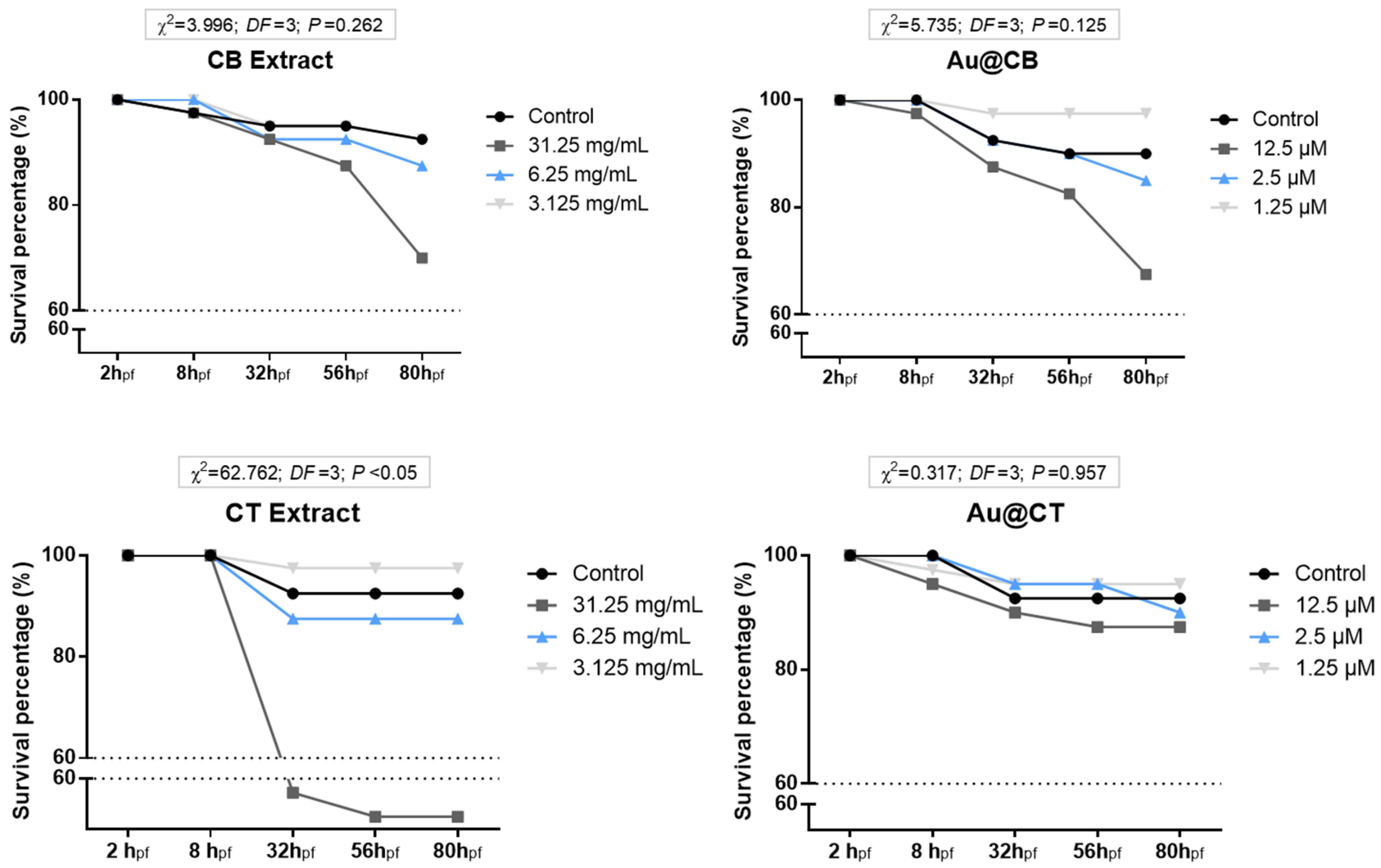

Figure 7 Cumulative survival of zebrafish embryos exposed to CB and CT extracts ( $\mathbf{A}$ and $\mathbf{B}$, respectively), and the corresponding Au@CB and Au@CT (C and $\mathbf{D}$, respectively), for $80 \mathrm{~h}_{\mathrm{pf}}$. 
primary toxicity caused by the algae extract itself, since a general (concentration-independent) inert outline was observed (Figure 7C and D). On the contrary, Au@CB replicated the lethal effects measured on $\mathrm{CB}$ extract (Figure 7A and $\mathrm{C}$ ), at which the survival rate was maintained above $60 \%$ throughout embryonic development, and although a higher embryotoxic effect was detected at the highest (nominal) test concentration, no significant statistical differences were recorded among groups. Once a superior phenolic content was measured on CT extract, and because it seems to play an active role in the reducing power at the biosynthesis of nanoparticles, while preserving a higher free radical scavenging activity, the lower embryotoxicity demonstrated by Au@CT can be explained mostly by a more relevant antioxidant propensity, inherent to the CT extract used in the biosynthesis.

Table 3 summarizes the results of the statistical analysis on the different sub-lethal embryonic developmental parameters monitored throughout FET experiments (Table S1 presents the multivariate statistical analysis on zebrafish embryonic developmental traits and Figure S4 depicts representative images of embryos at $56 \mathrm{~h}_{\mathrm{pf}}$ in the different experimental groups). One interesting outcome to highlight is that, despite the fact that evident lethal effects were not detected at the earliest hours of development (see Figure 7), significant sub-lethal toxicity was readily recorded upon exposure to both algae extracts and their AuNPs. It is the case of the atypical (increased) epiboly percentage measured at the highest test concentration of CB extract, as compared to the control group (SNK data not shown). At the two highest test concentrations of CT extract and its nanoparticles, a decreasing trend was also recorded in epiboly percentage, as compared to the control group (SNK data not shown). However, a counter-effect to that registered with $\mathrm{CB}$ extract was detectable, pointing to a delayed start of the ventral migration of epibolic blastomeres. By the end of somitogenesis (around $24 \mathrm{~h}_{\mathrm{pf}}$ ), these early developmental defects are expected to cause a more significant impact, since organized multipart and functional structures are now capable to process the associated putative toxicity. ${ }^{54}$ The results obtained clearly support this statement, as a significant increment in statistically relevant sub-lethal toxicity was detected, evidenced as follows.

At the phylotypic (pre-hatching) period, ${ }^{54}$ a pierced chorionic barrier at its innermost layers envelops the developing embryos. ${ }^{55}$ Gas supply and advective nutrient transport are secured through structural pore channels. ${ }^{56}$ It is expected that the algae extracts and their nanoparticles cross these pores to reach the embryos. In fact, the average diameter of the chorionic barrier pore channels ${ }^{56}$ can perfectly accommodate passage of particles at the Cystoseira AuNPs size range. However, it should be considered that due to their inferior negative surface charge, Au@CT are possibly more predisposed than $\mathrm{Au} @ \mathrm{CB}$ to aggregate and, therefore, if large clusters are formed, the chorion can act as a selective (size-dependent) barrier, mechanically restricting their crossing through its pores.

Still at the phylotypic period, the growth of the lecithotrophic embryos relies exclusively on the content of lipids in the yolk sac, ${ }^{54}$ which makes it one of the most influential traits when it comes to talking about toxicity during

Table 3 Statistical Analysis of Lethal and Sub-Lethal Effects Detected on Zebrafish Embryonic Development Upon Exposure of CB or CT Extracts and Their AuNPs

\begin{tabular}{|c|c|c|c|c|c|}
\hline \multirow[t]{2}{*}{ Embryonic Development Parameters } & \multicolumn{5}{|c|}{ Exposed to } \\
\hline & $h_{p f}$ & CB Extract & CT Extract & Au@CB & Au@CT \\
\hline Epiboly & 8 & $F(3,73)=2.923 ; P<0.05$ & $F(3,76)=5.413 ; P<0.05$ & $F(3,74)=2.291 ; P=0.085$ & $F(3,74)=3.467 ; P<0.05$ \\
\hline Spontaneous movements & 32 & $\chi^{2}=11.962 ; \mathrm{DF}=3 ; P<0.05$ & $\chi^{2}=67.948 ; D F=3 ; P<0.05$ & $\chi^{2}=18.724 ; \mathrm{DF}=3 ; P<0.05$ & $\chi^{2}=4.919 ; D F=3 ; P=0.178$ \\
\hline Head-trunk angle & 32 & $F(3,69)=1.203 ; P=0.315$ & $F(2,53)=1.741 ; P=0.185$ & $F(3,68)=3.110 ; P<0.05$ & $F(3,7 I)=4.693 ; P<0.05$ \\
\hline Pupil surface (co-variance: eye surface & 32 & $F(3,69)=5.768 ; P<0.05$ & $F(2,53)=3.890 ; P<0.05$ & $F(3,67)=1.010 ; P=0.394$ & $F(3,7 I)=5.038 ; P<0.05$ \\
\hline Yolk volume (co-variance: egg volume) & 32 & $F(3,69)=9.525 ; P<0.05$ & $F(3,62)=99.641 ; P<0.05$ & $F(3,70)=23.020 ; P<0.05$ & $F(3,7 \mid)=1.638 ; P=0.188$ \\
\hline Heart rate & 32 & $F(3,53)=28.919 ; P<0.05$ & $F(2,27)=13.867 ; P<0.05$ & $F(3,55)=20.984 ; P<0.05$ & $F(3,36)=6.041 ; P<0.05$ \\
\hline Heart rate & 56 & $F(3,46)=6.512 ; P<0.05$ & $F(2,27)=1.570 ; P=0.226$ & $F(3,49)=83.760 ; P<0.05$ & $F(3,36)=20.95 ; P<0.05$ \\
\hline Hatching rate & 56 & $F(3,8)=2.505 ; P=0.133$ & $F(2,9)=6.387 ; P<0.05$ & $F(3,8)=8.497 ; P<0.05$ & $F(3,12)=9.229 ; P<0.05$ \\
\hline Yolk extension (co-variance: $L_{T}$ ) & 56 & $F(3,54)=0.392 ; P=0.759$ & $F(2,2 I)=0.214 ; P=0.809$ & $F(3,43)=1.257 ; P=301$ & $F(2,25)=2.203 ; P=0.131$ \\
\hline $\mathrm{L}_{\mathrm{T}}$ & 56 & $F(3,55)=14.283 ; P<0.05$ & $F(2,22)=0.641 ; P=0.536$ & $F(3,44)=80.863 ; P<0.05$ & $F(2,26)=2.292 ; P=0.121$ \\
\hline Free swimming & 80 & $\chi^{2}=26.329 ; \mathrm{DF}=3 ; P<0.05$ & $F(2,9)=0.285 ; P=0.758$ & $\chi^{2}=75.243 ; D F=3 ; P<0.05$ & $F(3,12)=0.475 ; P=0.705$ \\
\hline Cumulative survival rate & 80 & $\chi^{2}=3.996 ; \mathrm{DF}=3 ; P=0.262$ & $\chi^{2}=62.762 ; \mathrm{DF}=3 ; P<0.05$ & $\chi^{2}=5.735 ; \mathrm{DF}=3 ; P=0.125$ & $\chi^{2}=0.317 ; \mathrm{DF}=3 ; P=0.957$ \\
\hline
\end{tabular}


early development. In fact, ANCOVA results on yolk (ball) volume detected relevant effects caused by both algae extracts and Au@CB (but not by Au@CT). Since lipids are metabolically processed at the yolk sac prior to being used by the embryo itself, ${ }^{57}$ the greatly increased yolk volumes associated to exposure to both algae extract suggest a critical arrest in lipid metabolization that can energetically compromise the larvae onto growth. As embryo straightening occurs, the yolk extends along the developing trunk, matching at some point the largest yolk ball diameter. ${ }^{54}$ Although this yolk segment was not affected, increased pupil surfaces and decreased total body sizes were detected in association with incubation with CB extract and its AuNPs (see Table 3). A compromised lipid trafficking is expected to cause a delayed diffusion of these energetic molecules towards consumption sites. In addition to this, a lower head-trunk angle was measured, substantiating a lag on development.

Until the beginning of Prim-15 stage, embryonic movements are absent. ${ }^{54}$ It is precisely at this developmental age that unremitting involuntary contractions occur, decreasing along development until hatching. ${ }^{58}$ It was verified that exposure to both algae extracts and Au@CB affected this normally decelerating trend, which was instead significantly accelerated, culminating in a complete absence of spontaneous movements at the highest (nominal) test concentration of CT extract. On the contrary, no statistically relevant concentration-dependent effects on spontaneous movements were identified upon $\mathrm{Au} @ \mathrm{CT}$ exposure. Given that the neuronal substrate coordinating spontaneous movements is the primitive spinal cord, ${ }^{58}$ a neuroprotective effect by $\mathrm{Au} @ \mathrm{CT}$ is apparent. Moreover, it seems to be extended beyond hatching, as no significant differences were detected at later embryonic development on free swimming, another neuro-mediated behavior commanded by secondary neuromotor circuits responsive to inputs of a fully developed hindbrain. ${ }^{59}$

When analyzing the extruding dynamics, inconsistent percentages of hatched embryos were found at the highest test concentration of both algae extracts and their AuNPs, suggesting a dysfunctional activity of the hatching gland cells, which secrete proteolytic enzymes responsible for eggshell (chorion) softening and fracturing. ${ }^{60}$

Lastly, it is particularly interesting to highlight that it is at the eleuthero (post-hatching) stage that the chorionless larvae become greatly vulnerable to acute toxic risk, mostly due to the presence of a fully developed heart and blood circulatory network, ${ }^{54}$ capable of efficiently spreading nutrients and toxic agents across the organism. A completely functioning neurocircuit is also recognized, commanding a structured trafficking of key molecular factors. ${ }^{54}$ Also, interdependent metabolic pathways facilitate any toxic effect that may arise. ${ }^{54}$

As in other vertebrates, the heartbeat of zebrafish embryo is controlled by the hindbrain, ${ }^{59}$ which also coordinates free swimming. While it is not surprising that significant cardiotoxicity was detected upon incubation with CB extract and its AuNPs, as data collected at earlier ages pointed towards a milder neuroprotective effect, the statistically relevant reduction in heart rate caused by $\mathrm{CT}$ extract and $\mathrm{Au} @ \mathrm{CT}$ is intriguing. Moreover, when analyzing the other neuromuscular-coordinated behaviors screened (Table 3), it is evident that CT extract and its AuNPs are manifestly inert, ruling out a direct interference in the brain or secondary neuronal circuits. A possible explanation is that a cardiovascular developmental defect, not a neural one, might have occurred, possibly reducing blood flow and, consequently, slowing larvae growth. Supporting these assumptions, yolk sac and pericardial edemas were present in a few embryos, thus indicating endothelial vasculature hemorrhaging, which is concordant with cardiovascular impairment (see Figure 8). Furthermore, it has been demonstrated that an increased pericardial sac area moderately correlates to reduced body length. ${ }^{61}$ A minor impairment on heart and blood circulatory networks, insufficient to affect the total body length (see Table 3), is possibly caused by contact with CT extract and Au@CT, as a lower percentage of smaller edemas were recorded in comparison to $\mathrm{CB}$ extract and its AuNPs.

Post-hatching, chorionless larvae become lecithoexotrophic, relying on the energetic deposits at the yolk sac to feed, but also acquiring nutrients externally. ${ }^{54} \mathrm{As}$ these are in direct contact with the algae extracts and their AuNPs, their putative antioxidant content may compensate the yolk sac finite supply of antioxidants, if these are depleted under conditions of oxidative stress. As CT extract showed a superior phenolic content than that of $\mathrm{CB}$ extract, this difference may well underlie the distinct embryotoxic responses to each of these extracts.

Overall, toxicity data collected suggest that the lowest nominal concentrations tested are safe and appropriate to further evaluate the putative bioactivity of the algae extracts and AuNPs. Particularly, Au@CT are potentially more appealing for biomedical applications, where toxicity to normal cells and tissues is particularly critical. 


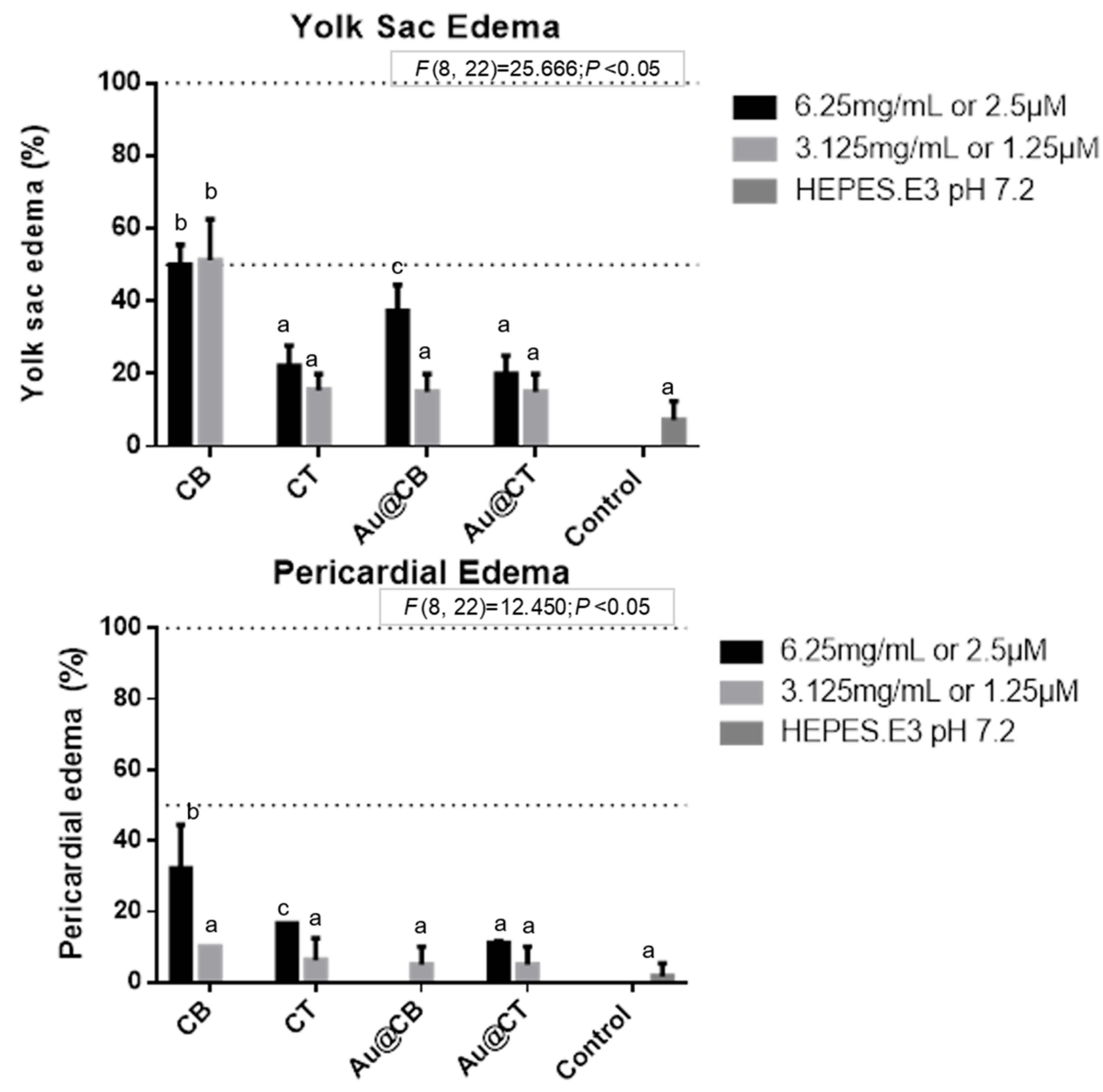

Figure 8 Yolk sac and pericardial edemas ( $\mathbf{A}$ and $\mathbf{B}$, respectively) detected on zebrafish embryos exposed to CB and CT extracts, and the corresponding Au@CB and $\mathrm{Au} @ \mathrm{CT}$, at 32 and $56 \mathrm{~h}_{\mathrm{pf}}$, respectively.

Notes: Error bars represent mean \pm standard deviation for two replicates, of two independent experiments. Different letters indicate significant differences among algae extracts and their AuNPs, as compared to control (one-factor ANOVA, $P<0.05$ ). It should be noted that the highest (nominal) test concentration is not represented due to the significant embryonic developmental delay recorded.

There are several studies on AuNPs that corroborate a general non-toxic effect to zebrafish and other aquatic organisms. $^{20}$ In developing zebrafish embryos, AuNPs were also reported as non-toxic in comparison with other metal-based nanoparticles, although being effectively uptaken by the embryos. ${ }^{62}$ This outcome is not dependent on nanoparticle size, ${ }^{63}$ particularly in the case of AuNPs, as only ultrasmall AuNPs (size $<0.2 \mathrm{~nm}$ ) exhibit cytotoxicity. ${ }^{64}$ Also, spherical AuNPs are associated with lesser toxicity risk. ${ }^{65}$ In adult zebrafish, biosynthesized AuNPs showed no toxicity, again compared to other metalbased nanoparticles. It is possible that the few existing reports on sub-lethal effects are identifying consequences of the coatings and, to a lesser extent, of their gold core. ${ }^{20}$

In general, current knowledge of biosynthesized AuNPs appears to corroborate our findings on Au@CB and Au@CT, given that similarly low toxicity was induced on normal cells and tissues of relevant vertebrate models, strongly supporting their safety for human use. The combination of bioactivity associated to algae extract components and the biosynthesized AuNPs thus arises as a remarkably interesting strategy for specific applications.

\section{In vitro Wound Healing Assay}

$\mathrm{CB}$ and CT algae extracts, and particularly Au@CT, exhibited a strong antioxidant profile, a characteristic which is highly relevant for biomedical applications, as skin wound healing. Furthermore, it is crucial that cell viability and migration are not negatively affected. A wound healing in vitro assay was therefore performed to investigate this possible use of the Cystoseira extracts and their AuNPs. The assay was performed considering two different 
strategies: pre- and post-incubation, taking into account the timing of the scratch. The algae extracts or their AuNPs could potentially exercise a protective effect (preincubation test), or alternatively, promote regeneration (post-incubation test). In both cases, the percentage of the free area in the confluent cell monolayer after the scratch was compared to the control. In this way, it was possible to determine whether the scratch was closed faster or slower than the control. The results were normalized in relation to their respective starting time (that is $0 \mathrm{~h}$ ), which was considered as $100 \%$ of free area percentage, and represented by the line $\mathrm{Y}=100$ in all the graphs. The two lowest test concentrations used on in vitro and in vivo testing were considered, due to their lower toxicity compared to the highest test concentration assessed (Figures 6 and 7).

For the pre-exposure strategy, MANOVA results on L929 revealed that none of the tested conditions led to significant differences in relation to the control experiments (Figure 9). Therefore, neither the algae extracts nor their AuNPs protected the cells from the inflicted scratch.

In the post-exposure assay, the algae extracts did not induce a positive effect on the L929 closure of the scratch (see Figure 10), possibly due to an interference with the migration patterns of these fibroblasts, which must be further studied. At the same time, Au@CT and Au@CB did not significantly affect the cells at any concentration.

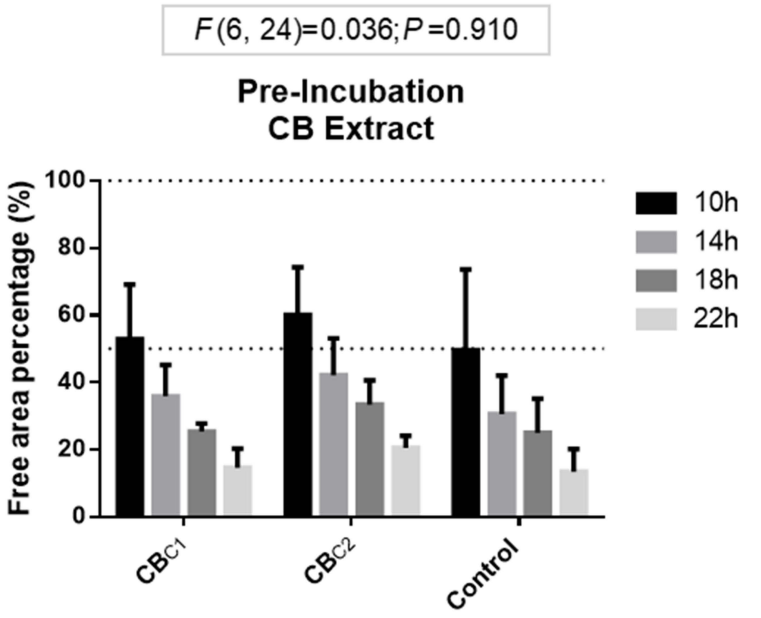

Extract concentrations (mg/mL)

$$
F(6,24)=0.358 ; P=0.898
$$

Pre-Incubation Au@CB

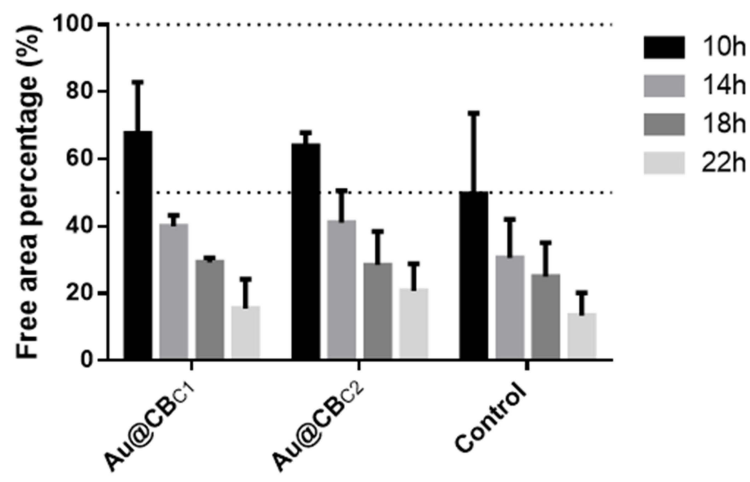

Au@CB concentrations ( $\mu \mathrm{M})$

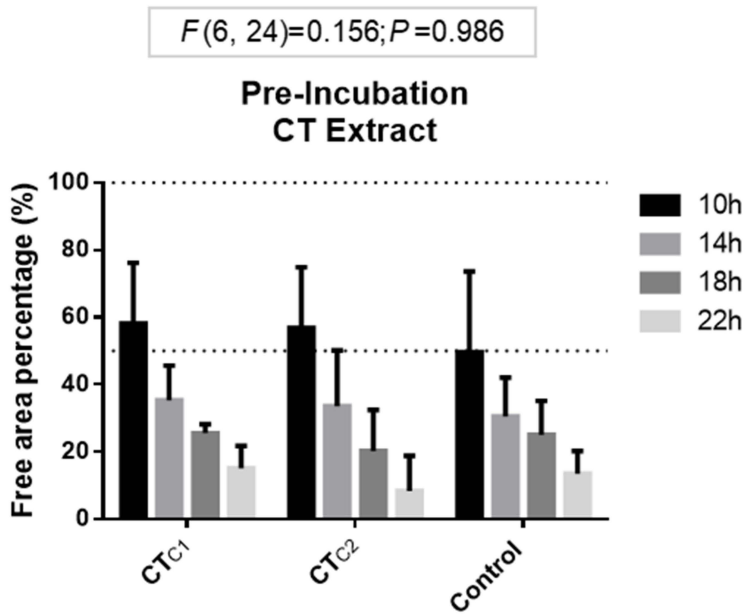

Extract concentrations $(\mathrm{mg} / \mathrm{mL})$

$F(6,24)=0.106 ; P=0.995$

Pre-Incubation Au@CT

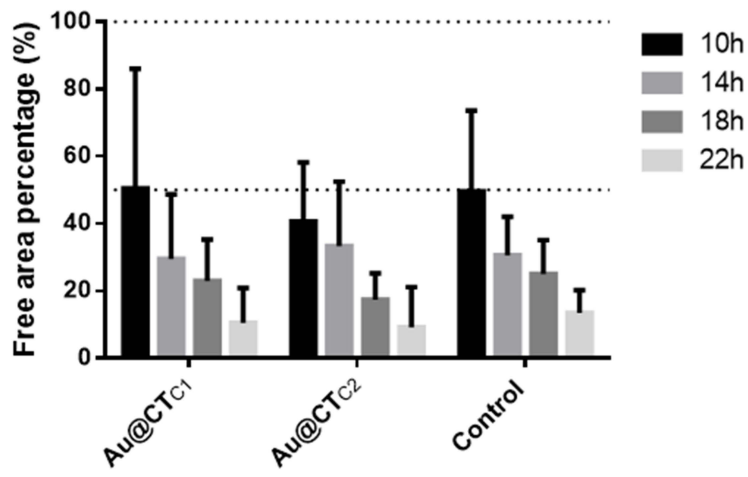

Au@CT concentrations ( $\mu \mathrm{M})$

Figure 9 Wound-healing assay data for pre-incubation of CB and CT extracts ( $\mathbf{A}$ and B, respectively), and the corresponding Au@CB and Au@CT (C and D, respectively), in mammalian (L929, mouse) fibroblast cells.

Notes: Error bars represent mean \pm SEM of three independent experiments. Different letters indicate significant differences among (nominal) test concentrations of the algae extracts and their AuNPs, independently. 


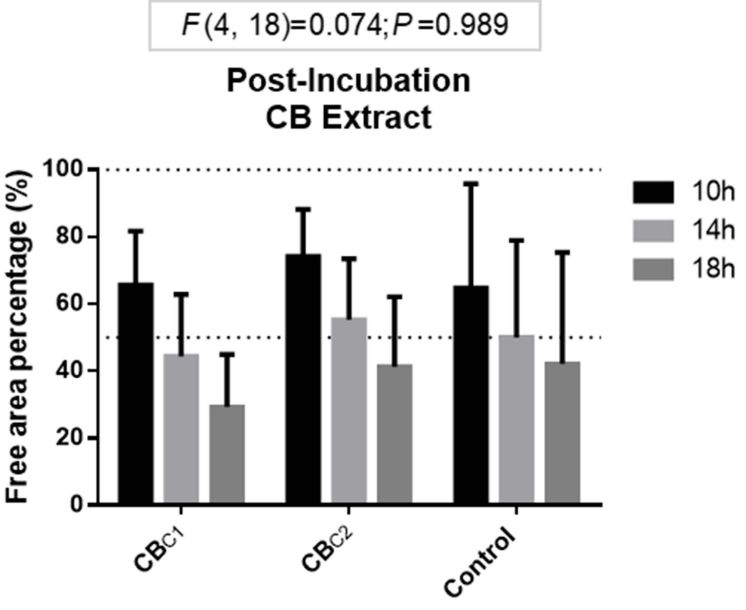

Extract concentrations ( $\mathrm{mg} / \mathrm{mL}$ )
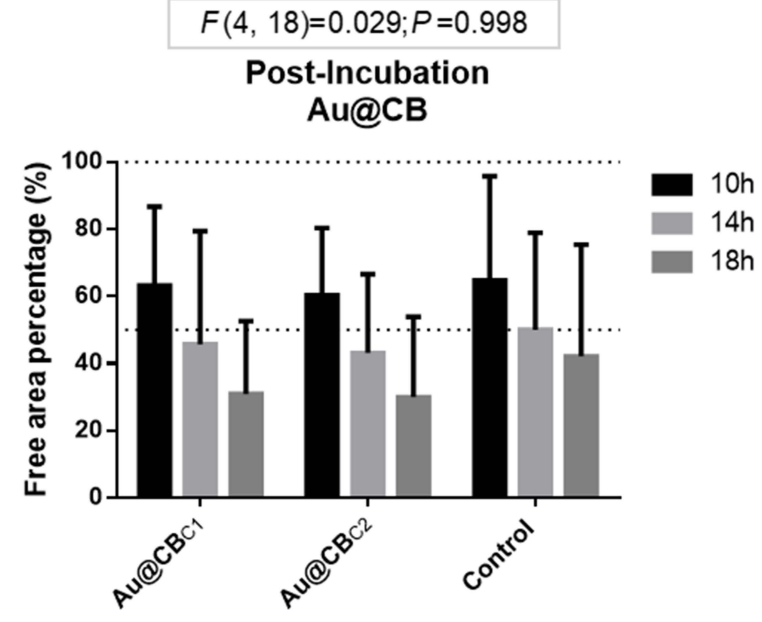

Au@CB concentrations ( $\mu \mathrm{M})$
$F(4,18)=0.146 ; P=0.963$

Post-Incubation

CT Extract

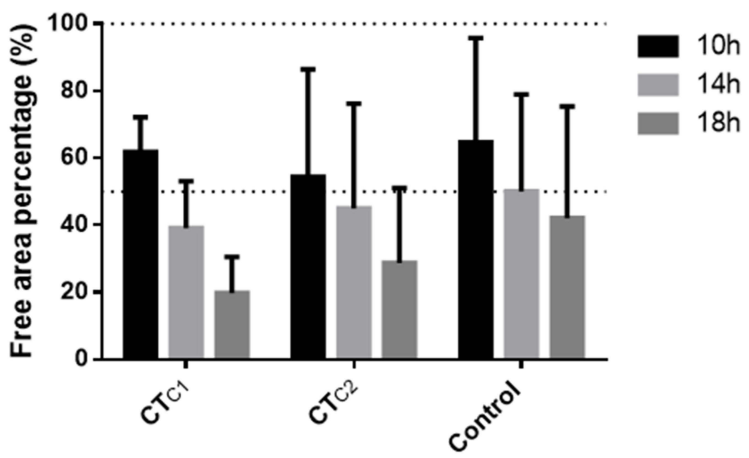

Extract concentrations $(\mathrm{mg} / \mathrm{mL})$

$F(4,18)=0.040 ; P=0.997$

Post-Incubation

Au@CT

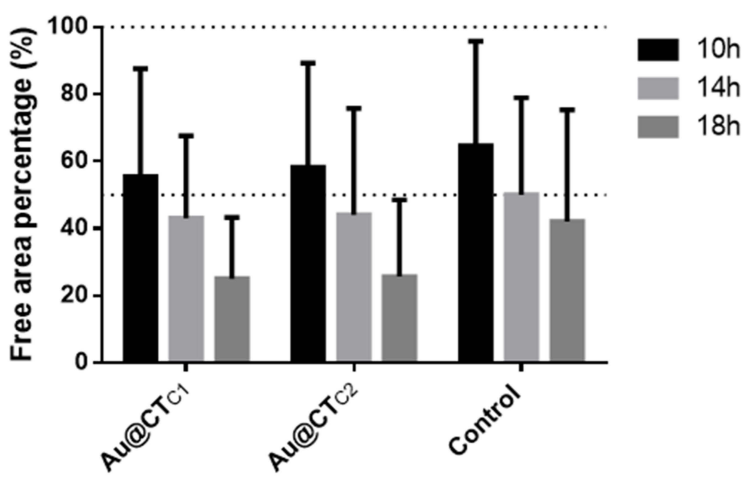

Au@CT concentrations $(\mu \mathrm{M})$

Figure 10 Wound-healing assay data for post-incubation CB and CT extracts (A and B, respectively), and the correspondent Au@CB and Au@CT (C and D, respectively), in mammalian (L929, mouse) fibroblast cells.

Notes: Error bars represent mean \pm SEM of three independent experiments. Different letters indicate significant differences among (nominal) test concentrations of the algae extracts and their AuNPs, independently.

L929 cells were also used in another work with a different algae species, Sargassum ilicifolium, and the results showed that cell proliferation and migration were significantly faster in those treated with aqueous extracts, in comparison with the control group, without inducing important cytotoxicity. ${ }^{66}$

Laminaran, a polysaccharide purified from the brown seaweed Cystoseira barbata, was studied for its effectiveness in healing full thickness wounds induced in rats presenting clear antioxidant and antibacterial properties, which led to improved collagen deposition and increased fibroblast and vascular densities. ${ }^{67}$ Therefore, as the algae studied are from the same genus, whose members share the presence of numerous bioactive compounds, it should be further investigated whether associated compounds are present in CT and CB extracts.

Taken as a whole, the results obtained indicate that neither the algae extracts nor their AuNPs, tested in nontoxic nominal concentrations, impaired proper cell migration. There may be a mild positive effect of CT extract and Au@CT that should be further explored, possibly in dermal keratinocytes, as these cells will be the first responders in terms of migration in a skin wound healing event. Regarding fibroblasts, the algae extracts and their AuNPs may influence the production of extracellular matrix, which together with the strong antioxidant potential, points to a possible anti-ageing use. 
The wound healing assays were replicated in BJ5ta cells with very similar results (see Figures $\mathrm{S} 2$ and $\underline{\mathrm{S} 3}$ ). Although without statistical significance, possibly due to the wide error bars, it is interesting to identify a trend towards a positive effect of post-incubation of either CT extract or Au@CT in these cells.

Due to the growing incidence of chronic wounds worldwide, with very few effective therapeutic solutions, there is a strong need for new solutions in the field of dermatology. Metal nanoparticles, including AuNPs, are increasingly being used for promoting wound healing, as in diabetic patients, due to a combination of beneficial effects. ${ }^{68-70}$ This study suggests that $\mathrm{Au} @ \mathrm{CT}$ may represent an extremely interesting, bio-sustainable alternative with applicability in this area.

\section{Conclusion}

A simple, environmentally friendly, low-cost and effective method was replicated for the efficient synthesis of colloidal AuNPs using for the first time an aqueous extract of the macroalgae $C$. tamariscifolia. The formation of these stable nanoparticles was demonstrated by UV-Vis spectroscopy, TEM, Z-potential and FTIR.

Regarding biomedical applications as the ultimate goal, the toxicological profiling of the algae extracts, $\mathrm{Au} @ \mathrm{CT}$ and Au@CB must be thoroughly studied to validate their use in humans. Algae extracts and AuNPs were generally non-toxic in the two fibroblast cell lines tested (mostly with concentrations under $6.25 \mathrm{mg} / \mathrm{mL}$ of $\mathrm{CB}$ or CT extracts, and $2.5 \mu \mathrm{M}$ of their AuNPs). Significant lethal effects were only noticeable at the highest (nominal) test concentration, which corresponds to non-physiological doses. The wound healing assay revealed that cell migration was not affected by the algae extracts or their AuNPs, with a potential positive effect of CT and Au@CT. AuNPs prepared with extracts of different algal species appear to cause dissimilar sublethal effects in zebrafish embryos, which may support their optimization for applications in which the susceptibility of normal cells may have different levels of importance.

\section{Ethical Statement}

The experiments comply with the current laws of the countries in which they were performed. FET assay was carried out up to $80 \mathrm{~h}_{\mathrm{pf}}$, in accordance with OECD ethical standards and, therefore, no additional ethical permits were required.

\section{Acknowledgments}

This work was supported by the strategic program UID/ BIA/04050/2020, funded by national funds through the FCT, IP, and the project "FUN2CYT: Harnessing the Potential for Biomedical Applications of Pleiotropic Cytokines LIF and Oncostatin M" (POCI-01-0145FEDER-030568), supported by Programa Operacional Competitividade e Internacionalização (FEDER) and FCT, IP. This work was further supported by Xunta de Galicia ED431C 2018/54-GRC. A. Gonçalves holds a fellowship from Fundação para a Ciência e a Tecnologia I.P. (FCT, IP) (SFRH/BD/146807/2019). We are extremely grateful to Dr. André da Costa for critical revision of the manuscript.

\section{Disclosure}

The authors report no conflicts of interest in this work.

\section{References}

1. Amini SM. Gold nanostructures absorption capacities of various energy forms for thermal therapy applications. $J$ Therm Biol. 2019;79:81-84.

2. Bouché M, Hsu JC, Dong YC, Kim J, Taing K, Cormode DP. Recent advances in molecular imaging with gold nanoparticles. Bioconjug Chem. 2020;31:303-314.

3. Goddard ZR, Marín MJ, Russell DA, Searcey M. Active targeting of gold nanoparticles as cancer therapeutics. Chem Soc Rev. 2020;49:8774-8789.

4. Kang MS, Lee SY, Kim KS, Han DW. State of the art biocompatible gold nanoparticles for cancer theragnosis. Pharmaceutics. 2020;12 (701):1-22.

5. Prado-López S, González-Ballesteros N, Rodríguez-Argüelles MC. Nanometals in cancer diagnosis and therapy. In: Zivic F, Affatato S, Trajanovic M, Schnabelrauch M, Grujovic N, Choy KL, editors. Biomaterial in Clinical Practice. Advances in Clinical Research and Medical Devices. Switzerland: Springer; 2018:407-428.

6. Yan L, Zhao F, Wang J, Zu Y, Gu Z, Zhao Y. A safe-by-design strategy towards safer nanomaterials in nanomedicines. Adv Mater. 2019;1805391:1-33.

7. Miller MR, Poland CA. Nanotoxicology: the need for a human touch? Small. 2020;16(2001516):1-12.

8. Zielinska A, Costa B, Ferreira MV, et al. Nanotoxicology and nanosafety: safety-by-design and testing at a glance. Int $J$ Environ Res Public Health. 2020;17(4657):1-23.

9. Dlugosz O, Szostak K, Staron A, Pulit-Prociak J, Banach M. Methods for reducing the toxicity of metal and metal oxide NPs as biomedicine. Materials. 2020;13(2):279-298.

10. Lee KX, Shameli K, Yew YP, et al. Recent developments in the facile bio-synthesis of gold nanoparticles (AuNPs) and their biomedical applications. Int J Nanomedicine. 2020;15:275-300.

11. Kalimuthu K, Cha BS, Kim S, Park KS. Eco-friendly synthesis and biomedical applications of gold nanoparticles: a review. Microchem J. 2020;152:104296-104315.

12. González-Ballesteros N, Rodríguez-Argüelles MC. Seaweeds: a promising bionanofactory for ecofriendly synthesis of gold and silver nanoparticles. In: Torres MD, Kraan S, Dominguez H, editors. Advances in Green and Sustainable Chemistry. Sustainable Seaweed Technologies Cultivation, Biorefinery, and Applications. 1st ed. Elsevier; 2020:507-541. 
13. Bruno de Sousa C, Gangadhar KN, Macridachis J, et al. Cystoseira algae (fucaceae): update on their chemical entities and biological activities. Tetrahedron Asymmetry. 2017;28(11):1486-1505.

14. Ammar HH, Lajili S, Said RB, Cerf DL, Bouraoui A, Majdoub H. Physico-chemical characterization and pharmacological evaluation of sulfated polysaccharides from three species of Mediterranean brown algae of the genus. DARU J Pharmaceutical Sci. 2015;23(1):1-8.

15. Vizetto-Duarte C, Custódio L, Acosta G, et al. Can macroalgae provide promising anti-tumoral compounds? A closer look at Cystoseira tamariscifolia as a source for antioxidant and anti-hepatocarcinoma compounds. PeerJ. 2016;4:e1704-e1704.

16. Vizetto-Duarte C, Custódio L, Gangadhar KN, et al. Isololiolide, a carotenoid metabolite isolated from the brown alga Cystoseira tamariscifolia, is cytotoxic and able to induce apoptosis in hepatocarcinoma cells through caspase- 3 activation, decreased bcl-2 levels, increased p53 expression and PARP cleava. Phytomedicine. 2016;23 (5):550-557.

17. Alarif WM, Basaif SA, Badria FA, Ayyadd SN. Two new cytotoxic C-29 steroids from the red sea brown alga Cystoseira Trinodis. Chem Nat Comp. 2015;51(4):697-702.

18. Klebowski B, Depciuch J, Parlinska-Wojtan M, Baran J. Applications of noble metal-based nanoparticles in medicine. J Mol Sci. 2018;19 (4031):1-17.

19. Daraee H, Eatemadi A, Abbasi E, Aval SF, Kouhi M, Akbarzadeh A. Application of gold nanoparticles in biomedical and drug delivery. Artif Cells Nanomed Biotechnol. 2016;44(1):410-422.

20. Bai C, Tang M. Toxicological study of metal and metal oxide nanoparticles in zebrafish. J Applied Toxicol. 2020;40(1):37-63.

21. Botha TL, Brand SJ, Ikenaka Y, Nakayama SMM, Ishizuka M, Wepener V. How toxic is a non-toxic nanomaterial: behaviour as an indicator of effect in Danio rerio exposed to nanogold. Aquatic Toxicology. 2019;215:105287-105297.

22. Dumitrescu E, Wallace K, Andreescu S. Nanotoxicity assessment using embryonic zebrafish. Methods Mol Biol. 2019;1894:331-343.

23. Haque E, Ward AC. Zebrafish as a model to evaluate nanoparticle toxicity. Nanomaterials. 2018;8:561.

24. Pereira AC, Gomes T, Machado MRF, Rocha TL. The zebrafish embryotoxicity test (ZET) for nanotoxicity assessment: from morphological to molecular approach. Environ Pollut. 2019;252:1841-1853.

25. Liu H, Wang X, Wu Y, et al. Toxicity responses of different organs of zebrafish (Danio rerio) to silver nanoparticles with different particle sizes and surface coatings. Environ Pollut. 2019;246:414-422.

26. Khoshnamvand M, Hao Z, Fadare OO, Hanachi P, Chen Y, Liu J. Toxicity of biosynthesized silver nanoparticles to aquatic organisms of different trophic levels. Chemosphere. 2020;258:127346.

27. Aksakal FI, Sisman T. Developmental toxicity induced by $\mathrm{Cu}(\mathrm{OH})_{2}$ nanopesticide in zebrafish embryos. Environ Toxicol. 2020;35: 1289-1298.

28. Pereira AC, Gonçalves BB, Brito RS, Vieira LG, Lima ECO, Rocha TL. Comparative developmental toxicity of iron oxide nanoparticles and ferric chloride to zebrafish (Danio rerio) after static and semi-static exposure. Chemosphere. 2020;254:126792.

29. Tang T, Zhang Z, Zhu X. Toxic effects of $\mathrm{TiO}_{2}$ NPs on zebrafish. Int J Environ Res Public Health. 2019;16:523.

30. González-Ballesteros N, Prado-López S, Rodríguez-González JB, Lastra-Valdor M, Rodríguez-Argüelles MC. Green synthesis of gold nanoparticles using brown seaweed Cystoseira baccata: its activity in colon cancer cells. Colloids Surf B Biointerfaces. 2017;153:190-198.

31. González-Ballesteros N, Rodríguez-González JB, Lastra-Valdor M, Rodríguez-Argüelles MC. New application of two Antarctic macroalgae Palmaria decipiens and Desmarestia menziesii in the synthesis of gold and silver nanoparticles. Polar Sci. 2018;15:49-54.

32. Wang $H$, Cheng $H$, Wang $F$, Wei D, Wang $X$. An improved 3-(4,5-dimethylthiazol-2-yl)-2,5-diphenyl tetrazolium bromide (MTT) reduction assay for evaluating the viability of Escherichia coli cells. J Microbiol Methods. 2010;82(3):330-333.
33. Gellert G, Heinrichsdorff J. Effect of age on the susceptibility of zebrafish eggs to industrial wastewater. Water Res. 2001;35 (15):3754-3757.

34. Mohapatra DP, Brar SK, Daghrir R, et al. Photocatalytic degradation of carbamazepine in wastewater by using a new class of whey-stabilized nanocrystalline $\mathrm{TiO}_{2}$ and $\mathrm{ZnO}$. Sci Total Environ. 2014;485:263-269.

35. Bhattacharjee S. DLS and zeta potential - what they are and what they are not? J Control Release. 2016;235:337-351.

36. Ainane T, Abourriche A, Kabbaj M. Physico-chemical analysis by SEM-EDX and FTIR two brown algae Cystoseira tamariscifolia and Bifurcaria bifurcata. Anal Chem. 2007;6(2):4-8.

37. Vizetto-Duarte C, Custódio L, Barreira L, et al. Proximate biochemical composition and mineral content of edible species from the genus Cystoseira in Portugal. Bot Mar. 2016;59 (4):251-257.

38. Rodrigues D, Freitas AC, Pereira L, et al. Chemical composition of red, brown and green macroalgae from buarcos bay in central west coast of Portugal. Food Chem. 2015;183:197-207.

39. Balboa EM, Gallego-Fabrega C, Moure A, Dominguez H. Study of the seasonal variation on proximate composition of oven-dried Sargassum muticum biomass collected in Vigo ria, Spain. J Appl Phycol. 2016;28(3):1943-1953.

40. Belattmani Z, El Atouani S, Kaidi S, et al. Protonated biomass of the brown seaweed Cystoseira tamariscifolia: a potential biosorbent for toxic chromium ions removal. Res J Environ Sci. 2018;12 (3):106-113.

41. Zhu B, Ni F, Xiong Q, Yao Z. Marine oligosaccharides originated from seaweeds: source, preparation, structure, physiological activity and applications. Crit Rev Food Sci Nutr. 2020. doi:10.1080/ 10408398.2020.1716207

42. Fernández PV, Ciancia M, Estévez JM. Cell wall variability in the green seaweed Codium vermilara (bryopsidales chlorophyta) from the Argentine coast. J Phycol. 2011;47:802-810.

43. Estévez JM, Fernández PV, Kasulin L, Dupree P, Ciancia M. Chemical and in situ characterization of macromolecular components of the cell walls from the green seaweed Codium fragile. Glycobiology. 2009;19(3):212-228.

44. Tabarsa M, You S, Dabaghian EH, Surayot U. Water-soluble polysaccharides from Ulva intestinalis: molecular properties, structural elucidation and immunomodulatory activities. J Food Drug Anal. 2018;26(2):599-608.

45. El-Rafie H, El-Rafie M, Zahran MK. Green synthesis of silver nanoparticles using polysaccharides extracted from marine macro algae. Carbohydr Polym. 2013;96(2):403-410.

46. Alipour HJ, Rezaei M, Shabanpour B, Tabarsa M. Effects of sulfated polysaccharides from green alga Ulva intestinalis on physicochemical properties and microstructure of silver carp surimi. Food Hydrocoll. 2018;74:87-96.

47. Abdala-Diaz RT, Cabellor-Pasisni A, Márquez-Garrido E, LópezFigueroa F. Intra-thallus variation of phenolic compounds, antioxidant activity, and phenolsulphatase activity in Cystoseira tamariscifolia (phaeophyceae) from southern Spain. Cienc Mar. 2014;40(1):1-10.

48. Celis-Plá PSM, Bouzon ZL, Hall-Spencer JM, Schmidt EC, Korbee N, Figueroa FL. Seasonal biochemical and photophysiological responses in the intertidal macroalga Cystoseira tamariscifolia (ochrophyta). Mar Environ Res. 2016;115:89-97.

49. Custódio L, Silvestre L, Rocha MI, et al. Methanol extracts from cystoseira tamariscifolia and Cystoseira nodicaulis are able to inhibit cholinesterases and protect a human dopaminergic cell line from hydrogen peroxide-induced cytotoxicity. Pharm Biol. 2016;54 (9):1687-1696.

50. Pinteus S, Silva J, Alves C, et al. Cytoprotective effect of seaweeds with high antioxidant activity from the Peniche coast (Portugal). Food Chem. 2017;218:591-599. 
51. Samri N, Hsaine L, El Kafhi S, Khlifi S, Etahiri S. Radical scavenging activity and phenolic contents of brown seaweeds harvested from the coast of Sidi Bouzid (El Jadida, Morocco). Int $J$ Pharm Sci Rev Res. 2019;54(21):116-122.

52. Andrade PB, Barbosa M, Matos RP, et al. Valuable compounds in macroalgae extracts. Food Chem. 2013;138:1819-1828.

53. Ramachandran R, Krishnaraj C, Kumar VKA, Harper SL, Kalaichelvan TP, Yun SI. In vivo toxicity evaluation of biologically synthesized silver nanoparticles and gold nanoparticles on adult zebrafish: a comparative study. Biotech. 2018;8(441).

54. Kimmel CB, Ballard WW, Kimmel SR, Ullmann B, Schilling TF. Stages of embryonic development of the zebrafish. Dev Dyn. 1995;203(3):253-310

55. Bonsignorio D, Perego L, Del Giacco L, Cotelli F. Structure and macromolecular composition of the zebrafish egg chorion. Zygote. 1996;4(2):101-108.

56. Rawson DM, Zhang T, Kalicharan D, Jongebloed WL. Field emission scanning electron microscopy and transmission electron microscopy studies of the chorion, plasma membrane and syncytial layers of the gastrula-stage embryo of the zebrafish Brachydanio rerio: a consideration of the structural and functional relationships with respect to cryoprotectant penetration. Aquaculture Res. 2000; 31:325-336.

57. Fraher D, Sanigorski A, Mellett NA, Meikle PJ, Sinclair AJ, Gibert Y. Zebrafish embryonic lipidomic analysis reveals that the yolk cell is metabolically active in processing lipid. Cell Rep. 2016;14(6):1317-1329.

58. Saint-Amant L, Drapeau P. Time course of the development of motor behaviors in the zebrafish embryo. J Neurobiol. 1998;37(4):622-632.

59. Kinkhabwala A, Riley M, Koyama M, et al. A structural and functional ground plan for neurons in the hindbrain of zebrafish. Proc Natl Acad Sci USA. 2011;108(3):1164-1169.

60. Fuiman LA. Special considerations of fish eggs and larval. In: Fuiman LA, Werner RG, editors. Fishery Science: The Unique Contributions of Early Life Stage. Oxford: Blacwell Science; 2002:1-32.
61. Teixidó E, Barenys M, Piqué E, Llobet JM, Gómez-Catalán J. Cardiovascular effects of PCB 126 (3,3',4,4',5-pentachlorobiphenyl) in zebrafish embryos and impact of co-exposure to redox modulating chemicals. Int J Mol Sci. 2019;20(5):1065.

62. Asharani PV, Lianwu Y, Gong Z, Valiyaveettil S. Comparison of the toxicity of silver, gold and platinum nanoparticles in developing zebrafish embryos. Nanotoxicology. 2011;5:43-54.

63. Bar-Ilan O, Albrecht RM, Fako VE, Furgeson DY. Toxicity assessments of multisized gold and silver nanoparticles in zebrafish embryos. Small. 2009;5(16):1897-1910.

64. Schmid G, Kreyling WG, Simon U. Toxic effects and biodistribution of ultrasmall gold nanoparticles. Arch Toxicol. 2017;91(9):30 11-3037.

65. Patibandla S, Zhang Y, Tohari AM, et al. Comparative analysis of the toxicity of gold nanoparticles in zebrafish. J Appl Toxicol. 2018;38 (8):1153-1161.

66. Premarathna AD, Ranahewa TH, Wijesekera SK, et al. Wound healing properties of aqueous extracts of Sargassum ilicifolium: an in vitro assay. Wound Medicine. 2019;24(1):1-7.

67. Sellimi S, Maalej H, Rekik DM, et al. Antioxidant, antibacterial and in vivo wound healing properties of laminaran purified from Cystoseira barbata seaweed. Int J Biol Macromol. 2018;11 9:633-644.

68. Nethi SK, Das S, Patra CR, Mukherjee S. Recent advances in inorganic nanomaterials for wound-healing applications. Biomater Sci. 2019;7(7):2652-2674.

69. Mihai MM, Dima MB, Dima B, Holban AM. Nanomaterials for wound healing and infection control. Materials. 2019;12(13):2176.

70. Vijayakumar V, Samal SK, Mohanty S, Nayak SK. Recent advancements in biopolymer and metal nanoparticle-based materials in diabetic wound healing management. Int $J$ Biol Macromol. 2019;122:137-148.
International Journal of Nanomedicine

\section{Publish your work in this journal}

The International Journal of Nanomedicine is an international, peerreviewed journal focusing on the application of nanotechnology in diagnostics, therapeutics, and drug delivery systems throughout the biomedical field. This journal is indexed on PubMed Central, MedLine, CAS, SciSearch ${ }^{\mathbb{R}}$, Current Contents ${ }^{\mathbb{R}} /$ Clinical Medicine, $^{2}$

\section{Dovepress}

Journal Citation Reports/Science Edition, EMBase, Scopus and the Elsevier Bibliographic databases. The manuscript management system is completely online and includes a very quick and fair peer-review system, which is all easy to use. Visit http://www.dovepress.com/ testimonials.php to read real quotes from published authors. 